\title{
Adverse Outcome Pathway: Peroxisome Proliferator-Activated Receptor $\alpha$ Activation and Reproductive Toxicity-Development and Application in Assessment of Endocrine Disruptors/Reproductive Toxicants
}

\author{
Małgorzata Nepelska, Jenny Odum,2 and Sharon Munn ${ }^{1}$
}

\begin{abstract}
In the process of a paradigm shift in toxicity testing, many efforts have focused on how to integrate and interpret information for biological events occurring at molecular and cellular level to be predictive of adverse effects at organism or population level to be useful, for example, for regulatory decision-making. The adverse outcome pathway (AOP) concept provides such a framework of knowledge-based safety assessment of chemicals that links mechanistic information with an apical endpoint. Here we outline an AOP that links the activation of peroxisome proliferator-activated receptor $\alpha(\operatorname{PPAR} \alpha)$ to reproductive tract malformations and impaired fertility in males. The development of this AOP relies on evidence collected from rodent models and incorporates human mechanistic and epidemiological data. Interest in PPAR $\alpha$ action as a mechanistic basis for effects on the reproductive system arises from the relationships between activation of this receptor and impairment of steroidogenesis leading to reproductive toxicity. The PPAR $\alpha$-initiated AOP is a first step for structuring current knowledge about mode of action (MoA), which is neither androgen receptor-mediated nor via direct aromatase inhibition. In the current form, the pathway lays a strong basis for linking an endocrine MoA with an adverse effect, a prerequisite requirement for the identification of endocrine disrupting chemicals.
\end{abstract}

Keywords: adverse outcome pathway (AOP), endocrine disruption, peroxisome proliferator-activated receptors (PPARs), reproductive toxicity, risk assessment, steroidogenesis

\section{Introduction}

$\mathbf{T}$ HE INTERACTION OF SUBSTANCES with hormonal pathways and their potential effects on human health has become a cause of public and regulatory concern in recent years. ${ }^{1}$ Such interactions may be transient and compensated for by endogenous feedback control mechanisms or may cause adverse effects on health and reproduction. Substances that affect endocrine systems may be termed "endocrine active substances" (EASs), while those that go on to produce adverse health effects are termed "endocrine disruptors" (EDs). The definition of an ED according to the WHO/IPCS is " An ED is an exogenous substance or mixture that alters function(s) of the endocrine system and consequently causes adverse health effects in an intact organism, or its progeny, or (sub)populations.,"2

Endocrine activity involves a range of biological pathways, including (but not limited to) estrogen, androgen, thyroid, peroxisome proliferator-activated receptors (PPARs), retinoids, and actions through other nuclear receptors. A variety of man-made chemical classes such as synthetic drugs and pesticides and naturally occurring substances (e.g., genistein, daidzein) are active toward endocrine systems in biological organisms. With hormones orchestrating virtually all physiological processes, the identification of relevant (in vivo) endpoints that indicate specific perturbation of endocrine processes is challenging. This makes it difficult to identify and hence regulate substances that can (potentially)

\footnotetext{
${ }^{1}$ European Commission, Joint Research Centre (JRC), Directorate F-Health, Consumers and Reference Materials, Chemical Safety and Alternative Methods, Ispra, Italy.

${ }^{2}$ Regulatory Science Associates, Kip Marina, Inverkip, Renfrewshire, England.

(c) Małgorzata Nepelska et al. 2017; Published by Mary Ann Liebert, Inc. This is an Open Access article distributed under the terms of the Creative Commons Attribution License, which permits unrestricted use, distribution, and reproduction in any medium, provided the original work is properly cited.
} 
cause adverse effects by disrupting the endocrine system. The OECD has had a program of test guideline development for identifying substances that may be EASs or EDs since the late 1990s. Many new tests have been validated and older tests updated (e.g., OECD TG 443, 407). The "toolbox" of tests can be found in the OECD Conceptual Framework for Testing and Assessment of EDs. ${ }^{3}$

In addition, new approaches to understand the mechanisms of toxicity, including endocrine disruption, are being explored; one of them being adverse outcome pathways (AOPs). ${ }^{4}$ An AOP is an analytical construct that describes a sequential chain of causally linked events at different levels of biological organization that lead to an adverse health or ecotoxicological effect. AOPs are the central element of a toxicological knowledge framework being built to support chemical risk assessment based on mechanistic reasoning. Organization of existing knowledge into AOP descriptions provides a systematic and transparent assembly of the evidence that supports extrapolation from initial or intermediate measures of biological perturbation to useful predictions of potential hazard. With this in mind, an AOP describes key building blocks, key events (KEs), and key event relationships (KERs) linking a molecular initiating event (MIE) and adverse outcome (AO), in sufficient detail to support the application of a wide range of mechanistically based data in risk assessment and regulatory decision-making.

The OECD has undertaken a major activity of supporting the development of AOPs. ${ }^{5}$ The AOPs are captured in the AOP-Wiki (www.aopwiki.org), which is part of a broader AOP knowledge base (AOP-KB www.aopkb.org) whose elements are currently under development. The goal is to assemble a comprehensive collection of accessible AOPs that provide a base to develop new and more accurate safety assessment approaches for substances. The utility of AOPs for regulatory application is defined to a large extent by the confidence and precision with which they facilitate extrapolation of data measured at low levels of biological organization (often in vitro) to predict the higher level outcomes. In parallel, they promote the use of alternative methods increasing our understanding of biological processes and contributing to decreasing the use of animals in toxicological research.

This review describes an AOP (PPAR $\alpha$ activation in utero leading to reproductive tract malformations and impaired fertility in males) that was developed within the OECD AOP process. $^{6}$ Although the involvement of PPAR $\alpha$ in the pathway has been investigated for almost 20 years, its role is still under scientific discussion. ${ }^{7,8}$ The uncertainty and lack of adequate experiments confirming or refuting its role was recently expressed during the OECD organized review of this AOP in September 2015 (https://aopwiki.org/wiki/index.php/Review: OECD_External_Review_September,_2015_-_Aop:18). The reviewers supported the evidence calls as moderate to strong for all other subsequent KEs and KERs leading to the AO. This AOP, together with 12 other pioneer AOPs, was reviewed twice in a process managed by the OECD.

The first (internal) review took place in March 2015 and an external review followed in September 2015. In the internal review process, 3 experts nominated by the Extended Advisory Group on Molecular Screening and Toxicogenomics (EAGMST) checked compliance of the AOP structure and content with guidance documents. ${ }^{9}$ In the external part of the review process, scientific/technical content of the
AOP was assessed by six independent experts in the field. The external review was conducted by experts not involved in the development of the specific AOP, who had scientific expertise in the hazard area/endpoint covered by the AOP.

Due to the uncertainties connected to experimental data defining the role of PPAR $\alpha$ in the pathway, the external reviewers proposed two options: designate MIE as unknown or change to the next KE. Both of the options are not optimal as an AOP per definition should contain an MIE and designation of subsequent events as MIE would be more generic (e.g., decrease of steroidogenic enzymes). Currently, the final decision has not been made by the EAGMST. The final outcome of the review was that there was some uncertainty over the MIE, but the AOP as a whole provides a useful framework for regulatory chemical assessment, development of targeted testing strategies, and identifying further research needs.

\section{The Core Elements of the AOP}

The AOP was developed linking PPAR $\alpha$ activation with male reproductive/developmental-related adverse outcomes (found at AOP-Wiki: www.aopwiki.org/aops/18). The development of this AOP relies on the evidence collected from rodent models and incorporates human mechanistic and epidemiological data.

The KEs in the pathway comprise the activation of PPAR $\alpha$ (MIE), leading to decreases in translocator protein (TSPO; KE1a) and/or steroidogenic acute regulatory (StAR) protein (KE1b), the disruption of cholesterol transport in mitochondria (KE2), reduction in testosterone synthesis (KE3) and, hence, circulating hormones (KE4). This indirectly leads to the AOs of malformation of the reproductive tract in males (AO1) with impaired fertility (AO2) as a possible consequence (Fig. 1).

In its current form, the pathway lays a strong basis for linking an endocrine mode of action (MoA) with an adverse effect, a prerequisite requirement for the identification of EDs. Identifying the mechanism of action is important because some MoAs are known to operate in model species but not humans (or vice versa), meaning that the related adverse effect could be discounted (or accounted for) when considering relevance to man. The PPAR $\alpha$ is a ligand-activated transcription factor that belongs to the nuclear receptor family, which also includes the steroid and thyroid hormone receptors. Interest in PPAR $\alpha$ action as a mechanistic basis for effects on the reproductive system arises from the relationships between activation of this receptor and steroidogenesis, impairment of which may impact on fertility. ${ }^{10}$

PPARs play important roles in the metabolic regulation of lipids, of which cholesterol, in particular, being a precursor of steroid hormones, makes the link between effects on lipid metabolism and effects on reproduction.

The AOP draws heavily on data generated on data-rich chemicals (mainly phthalates) and aims to provide a means of systematic collection of relevant information, which could be used to assess reproductive toxicity potential. The phthalates are among the most widespread environmental contaminants worldwide. The wide exposure of the general population to phthalates ${ }^{11-13}$ has raised concern about possible detrimental health effects. ${ }^{14-17}$ Some phthalates are developmental and reproductive toxicants in rats, largely affecting the male reproductive system. ${ }^{18-24}$ The adverse endocrine effects of 


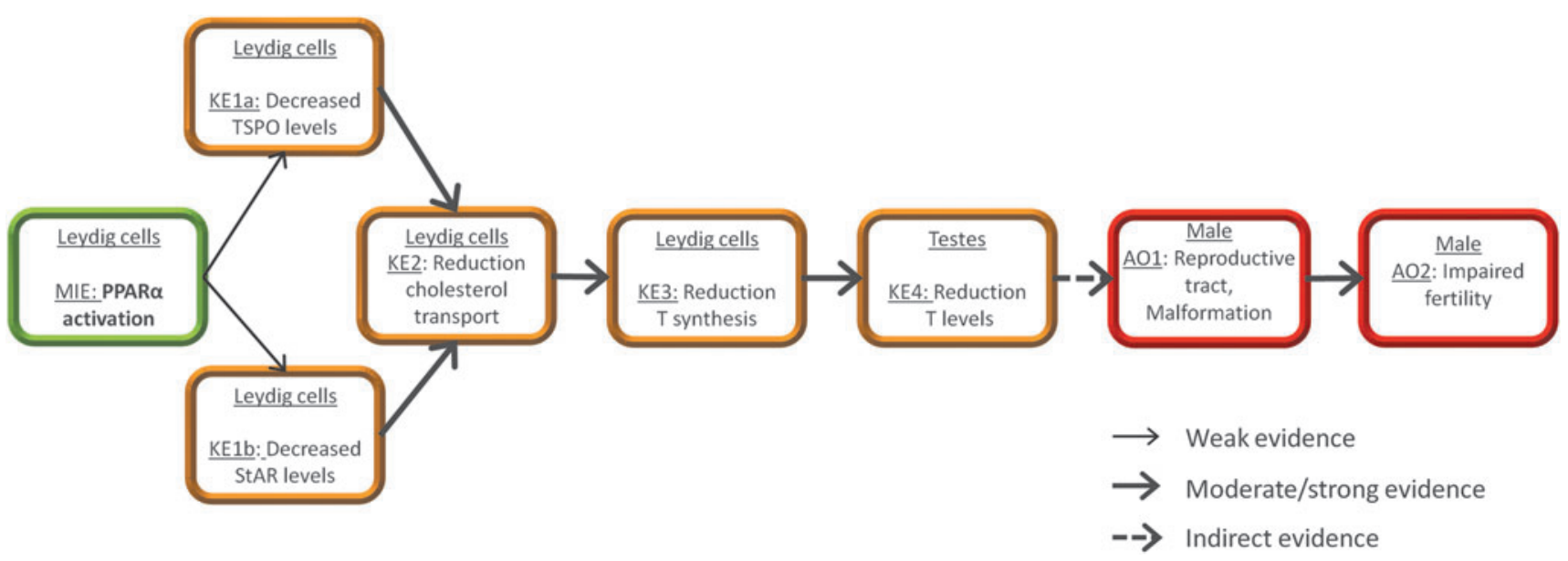

FIG. 1. The schematic representation of PPAR $\alpha$ activation in utero leading to impaired fertility in males. The narrow lines indicate weak key event relationships, whereas dashed lines indicate an indirect key event relationship. Green box represents the MIE; orange key, events that might lead to disturbance of homeostasis; in red, adverse outcomes. MIE, molecular initiating event; $\operatorname{PPAR} \alpha$, peroxisome proliferator-activated receptor $\alpha$.

antiandrogens, including the phthalates, have recently been shown to act in a dose-additive manner. ${ }^{7,25,26}$ Moreover, recent reviews of epidemiological and experimental data have concluded that phthalate antiandrogenicity is plausible in adult men. ${ }^{27,28}$ This underscores the importance of delineating this AOP, gaining further knowledge on its events, identifying chemicals acting via this MoA and understanding relevance of the pathway to humans.

The following sections describe the events of the AOP in detail, outlining the strength of evidence for the KEs and the relationships between them.

\section{MIE: PPAR $\alpha$ Activation in Leydig Cells}

The PPAR $\alpha$ belongs to the steroid/thyroid/retinoid receptor superfamily of transcription factors (NR1C). PPAR $\alpha$ is expressed at high levels in tissues that perform significant catabolism of fatty acids (FAs). ${ }^{29}$ The receptor is also present in skeletal muscle, intestine, pancreas, lung, placenta, and testes. $^{30,31}$ PPARs are activated by FAs and their derivatives. They are sensors of dietary lipids and are involved in lipid and carbohydrate metabolism, immune response, and peroxisome proliferation. $^{32,33}$

$\operatorname{PPAR} \alpha$ is also a target of hypothalamic hormone signaling and was found to play a role in embryonic development. ${ }^{34}$ According to the reviews of David, ${ }^{8}$ Latini et al., ${ }^{10}$ and Corton and Lapinskas, ${ }^{35}$ PPAR $\alpha$ activators have been shown to alter steroidogenesis and in consequence impair reproduction. In addition, a predictive model of rat reproductive toxicity based on more than 500 assays mapped to hundreds of genes and spanning many MoAs showed an association of PPAR $\alpha$ activity with reproductive toxicity. ${ }^{36}$ According to this model, $10 \operatorname{PPAR} \alpha$ agonists, including bis(2-ethylhexyl) phthalate (DEHP), mono(2-ethylhexyl) phthalate (MEHP), and perfluorooctanoic acid (PFOA), shared a relatively common reproductive toxicity profile of a decrease in reproductive performance (i.e., decreased fertility).

The PPAR family is composed of three isotypes (PPAR $\alpha$, $\operatorname{PPAR} \beta$, and PPAR $\gamma$ ). They form heterodimers with the retinoid $\mathrm{X}$ receptor (RXR) and adopt an active conformation in the presence of an agonist. The characteristic feature of the PPAR ligand binding cavity is its size, which is three to four times larger than that of the other nuclear receptors, which increases the number and type of chemical substances that may act as ligands. ${ }^{32}$ The capacity to fit and bind these diverse chemical structures results in distinctive gene expression profiles, which ultimately lead to different clinical outcomes. ${ }^{37,38}$ As an example, rosiglitazone is a full agonist for PPAR $\gamma$ exerting strong activation of adipogenic genes. In contrast, MEHP is only a partial agonist and showed only mild stimulation. ${ }^{38}$ Perturbation of PPAR signaling can also alter other nuclear receptor signaling pathways, such as the retinoic acid and thyroid hormone signaling pathways, by sequestering endogenous heterodimer binding partners (such as RXR). ${ }^{39,40}$ Nuclear receptor signaling via such nuclear pathways is essential for correct hormonal responses and interference may impact on both gonadal development and spermatogenesis that rely on the integrity of this signaling. 41,42

Therefore, the potential differential impact of interactions of different chemicals with PPARs and their related coactivators or corepressors on the nuclear signaling pathways needs to be considered.

Selected chemicals known to interact with the PPAR $\alpha$ are shown in Table 1. Although the evidence that PPAR $\alpha$ activation is the MIE in this AOP is contradictory (see KER: the relationship between activation of $\operatorname{PPAR} \alpha$ and decreased TSPO levels), there are experimental data indicating that $\operatorname{PPAR} \alpha$ is implicated in regulating reproductive function. ${ }^{43}$ The mechanistic link between PPAR $\alpha$ activity and fertility or other reproductive impairment is correlative, but the role of PPAR $\alpha$ in steroid metabolism and its activity in reproductive tissues allow us to infer that it is a plausible target for disruption of endocrine signaling and altered gametogenesis.

\section{$K E R$ : the relationship between activation of $P P A R \alpha$ and decreased TSPO levels}

Activation of PPAR $\alpha$ leads to decreased expression of the cholesterol transport (TSPO) gene in steroidogenic cells (e.g., Leydig cells). Consequently, the amount of cholesterol 
Table 1. Selected Chemicals That Interact with the Peroxisome Proliferator-Activated Receptor $\alpha$

\begin{tabular}{|c|c|c|}
\hline Group of chemicals & Chemicals & Comments and references \\
\hline Fibrates & Bezafibrate & $\begin{array}{l}\text { Ligands of PPAR } \alpha^{157} \text { used as hypolipidemic drugs-- } \\
\text { important therapeutic tools in the metabolic syndrome. } \\
\text { Bezafibrate was shown to decrease levels of steroidogenic } \\
\text { proteins (TSPO) in MA-10 Leydig cells }\end{array}$ \\
\hline \multirow[t]{3}{*}{ Phthalates } & MEHP & $\begin{array}{l}\text { Directly binds in vitro to PPAR } \alpha^{132} \text { and activates this } \\
\text { receptor in transactivation assays PPAR } \alpha^{132,158-162}\end{array}$ \\
\hline & DEHP & $\begin{array}{l}\text { DEHP is the parent compound from which MEHP is a } \\
\text { metabolite. The data on DEHP are inconsistent as it has } \\
\text { not been found to bind and activate PPAR } \alpha{ }^{132,158} \\
\text { However, recent studies have shown activation of PPAR } \alpha \\
\text { by DEHP }\end{array}$ \\
\hline & DBP & Activates PPAR $\alpha^{164}$ and decreases levels of $\mathrm{TSPO}^{43}$ \\
\hline Perfluorinated carboxylic acids & PFOA & Activates PPAR $\alpha^{165}$ \\
\hline Organotin & TBT & $\begin{array}{l}\text { Activates all three isoforms of PPAR (primarily through its } \\
\text { interaction with RXR) }\end{array}$ \\
\hline
\end{tabular}

DBP, dibutyl phthalate; DEHP, bis(2-ethylhexyl) phthalate; MEHP, mono(2-ethylhexyl) phthalate; PFOA, perfluorooctanoic acid; $\operatorname{PPAR} \alpha$, peroxisome proliferator-activated receptor $\alpha$; RXR, retinoid X receptor; TBT, tributyltin; TSPO, translocator protein.

transported into mitochondria decreases, impacting on steroid production.

PPARs regulate genes involved in cholesterol uptake and transport. ${ }^{44-46}$ The indirect link between PPARs and regulation of cholesterol transport in mitochondria derives from studies demonstrating PPAR $\alpha$-dependent control of TSPO. ${ }^{4,46}$ PPAR $\alpha$ is present in steroidogenic cells, for example, in testes during development as well as in adult testes $^{31,47}$; and modulation of its activity has been shown to impact on TSPO transcriptional activity. ${ }^{45}$

The exact nature of this relationship is not known, however, there is some evidence providing a basis for this hypothesis. Gazouli showed that PPAR $\alpha$ activators (bezafibrate, MEHP) inhibited the transfer or loading of cholesterol to the inner mitochondrial membrane in MA-10 mouse Leydig tumor cells and decreased levels of TSPO protein. In addition, these chemicals also inhibited the formation of progesterone (a precursor of testosterone) in R2C cells (rat Leydig tumor cell line). In vivo, levels of the TSPO protein were decreased in testes of adult mice exposed to DEHP (although DEHP is not a PPAR activator in vitro, it is metabolized to MEHP, which is its metabolite $)^{45}$ and the messenger RNA (mRNA) levels were decreased in a dose-dependent manner in fetal testes. Bezafibrate and phthalates inhibited both hormone-induced and constitutively sustained steroidogenesis with similar $\mathrm{IC}_{50}$ values, indicating that they act on a common regulatory component of the steroidogenic pathway. $^{45}$

There are, however, some uncertainties related to the involvement of PPAR $\alpha$ in regulation of TSPO. Treatment of adult mice with a PPAR $\alpha$ activator (DEHP or WY-14,643) resulted in reduced levels of circulating testosterone and testis TSPO mRNA, consistent with the in vitro effects. ${ }^{45}$ In contrast, liver TSPO mRNA levels have been increased, indicating a tissue-specific regulation of TSPO expression by PPAR $\alpha$ activators. $^{45}$ In untreated PPAR $\alpha$-null mice, compared with the wild-type controls, circulating testosterone levels were decreased suggesting a positive constitutive role for PPAR $\alpha$ in maintaining Leydig cell steroid formation. Surprisingly, treatment of the PPAR $\alpha$-null mice with PPAR $\alpha$ activators (DEHP and WY-14,643) restored testosterone formation and TSPO mRNA returned to normal levels, suggesting PPAR $\alpha$ independent pathways might be involved in the regulation of TSPO genes and steroidogenesis. ${ }^{45}$

In support of this hypothesis, other studies have demonstrated that part of the toxic effect of phthalate (DEHP) on testis was retained in $\operatorname{PPAR} \alpha$-null mice unlike effects in the liver, which were absent. ${ }^{48}$ However, because the null mice developed lesions in the testis, it indicated that DEHP can also act through PPAR $\alpha$-independent pathways in mediating testicular toxicity.

There is some evidence involving additional PPARs in transcriptional regulation of TSPO:

- PPAR $\beta / \delta$ (MEHP) was able to temporarily increase TSPO mRNA levels through the PPAR- $\alpha$ and $\beta / \delta$ pathways ${ }^{46}$;

- PPAR $\gamma$ isoform was also detected in rat fetal testes ${ }^{47}$ and it was reduced by treatment of DEHP in parallel with the reduction of TSPO regulation. ${ }^{49}$

One genomic study in rat fetal testes at gestation day (GD) 14-18 does not support the hypothesis that activation of PPAR $\alpha / \gamma$ pathways is involved in the effects of phthalates on sexual differentiation of the male rat, since the PPAR $\gamma$ isoform was not detected and, although PPAR $\alpha$ was present, a $\operatorname{PPAR} \alpha$ activator $(\mathrm{Wy}-14,643)$ had no effect on testosterone production. ${ }^{50}$ Also, differential patterns of TSPO expression in the fetal rat testis have been observed on phthalate (dibutyl phthalate $[\mathrm{DBP}])$ treatment. In whole-testis expression of TSPO, mRNA was upregulated, whereas protein levels were decreased in interstitial cells. ${ }^{51}$

\section{$K E R$ : the relationship between activation of PPAR $\alpha$ and decreased StAR levels}

The direct link between PPAR $\alpha$ regulation of cholesterol transport in mitochondria and hormone synthesis derives from studies demonstrating that PPAR $\alpha$ may act as an indirect transrepressor of the key steroidogenic factor-1 (SF-1). ${ }^{52,53}$ SF-1 is a transcription factor essential for expression of genes involved in steroidogenesis (including StAR). 
$\operatorname{PPAR} \alpha$ is expressed in fetal rat Leydig cells ${ }^{47,53}$ and in adult rat Leydig cells. ${ }^{31}$ Recent studies have shown that fetal testes contained $\operatorname{PPAR} \alpha$ protein-binding peaks in CYP11a, StAR, and CYP17a regulatory regions. ${ }^{53}$ Binding of PPAR $\alpha$ to the promoter region of steroidogenic genes occurs at binding sites different from those of SF-1, indicating that PPAR $\alpha$ may be an indirect repressor of SF-1 binding. Moreover, it is possible that PPAR $\alpha$ could act via sequestration of the shared coactivator CREB-binding protein $(\mathrm{CBP}){ }^{53} \mathrm{PPAR} \alpha$ and $\mathrm{SF}-1$ share $\mathrm{CBP}$, which is present in limited concentrations, ${ }^{54}$ and PPAR $\alpha$ and SF-1 may compete for binding to CBP. SF-1 controls transcription of the StAR gene. ${ }^{55}$ StAR protein plays a critical role in the movement of cholesterol from the outer to the inner mitochondrial membrane. ${ }^{56}$

Hence, it seems likely that the ability of PPAR $\alpha$ to interfere with SF-1 binding/transactivation caused by exposure to chemicals (e.g., phthalates) could affect StAR expression and cholesterol transport in mitochondria. PPAR $\alpha$ agonists have been shown to suppress Leydig cell steroidogenesis ${ }^{45}$ and downregulate steroidogenic genes, including StAR. ${ }^{49,51,57}$

Moreover, PPAR $\alpha$ agonists, which do not directly transrepress the StAR promoter, have been found to downregulate the expression of this gene in steroidogenic tissues (mouse ovaries). ${ }^{58}$

\section{KE 1a: Decreased TSPO Levels in Leydig Cells}

TSPO (previously known as the peripheral benzodiazepine receptor $[\mathrm{PBR}]$ ), is a mitochondrial outer membrane protein implicated in cholesterol import to the inner mitochondrial membrane. ${ }^{59}$ It mediates the delivery of the substrate cholesterol to the inner mitochondrial side chain cleavage cytochrome P-450. ${ }^{59}$ TSPO shows high sequence conservation from bacteria to mammals. It is expressed ubiquitously, but is most abundant in steroidogenic cells. ${ }^{60}$

TSPO is present in virtually all mammalian peripheral tissues. ${ }^{61}$ It has been implicated in many cellular processes; among these are steroid biosynthesis, protein import, heme biosynthesis, immunomodulation, cellular respiration, and oxidative processes. Although TSPO is present in virtually all mammalian peripheral tissues, TSPO protein expression is highly prominent in steroidogenic tissues. ${ }^{62,63}$ The presence of TSPO has been confirmed in Leydig and Sertoli cells, ${ }^{64}$ granulosa cells, ${ }^{65}$ and to a lesser extent in thecal cells. ${ }^{64}$

In subcellular fractions, binding sites for the TSPO have been identified to be present in the outer mitochondrial membrane. ${ }^{62,66}$ Transcriptional regulation of the TSPO gene has been reviewed recently. ${ }^{64}$

There are some contradictions with regard to function of TSPO protein. TSPO knockout mice showed embryonic lethality, ${ }^{67}$ however, recent findings have shown no effect on viability. ${ }^{68}$

Aberrant TSPO levels have been linked to multiple diseases, including cancer, endocrine disorders, brain injury, neurodegeneration, ischemia-reperfusion injury, and inflammatory diseases. ${ }^{63}$ However, recent studies have shown some contradictory results as PBR/TSPO global knockout mice were viable and there were no effects on steroid hormone biosynthesis. ${ }^{68,69}$ As stated in the recent review, "At this point in time, a functional designation for TSPO is still actively being sought."70

\section{KER: decreased TSPO levels lead to a reduction in cholesterol transport}

TSPO ligands stimulate steroidogenesis and induce cholesterol movement from the outer mitochondrial membrane to the inner mitochondrial membrane. ${ }^{59}$ Therefore, it follows that reduced activity of the TSPO will impair the delivery of cholesterol necessary for hormone biosynthesis.

Decreased TSPO protein levels have been shown to reduce cholesterol transport into mitochondria of mouse Leydig cells. ${ }^{45,49}$ Moreover, the uptake of cholesterol was decreased in Leydig cell mitochondria on exposure to phthalates. ${ }^{71}$

There are some uncertainties reported in the literature concerning this KER as reported under KE1a above. Whereas targeted disruption of TSPO in rat Leydig R2C cells led to reduced steroidogenesis, ${ }^{72}$ recent experiments involving TSPO knockdown in steroidogenic cells did not affect steroid hormone biosynthesis ${ }^{68}$ nor did specific deletion of TSPO in Leydig cells impair their synthesis of testosterone. ${ }^{69}$

\section{KE1b: Decreased StAR Levels in Leydig Cells}

StAR protein functions as a cholesterol transfer protein and acts directly on lipids of the outer mitochondrial membrane to promote cholesterol translocation. ${ }^{56}$ Reduction of the StAR impacts on the amount of substrate available for steroidogenesis. StAR is expressed principally in steroidogenic tissues. ${ }^{73}$ It has been cloned from many species and is highly conserved among mammals, birds, amphibians, and fish. ${ }^{73}$ StAR appears to regulate acute steroid production. ${ }^{74}$ Transcriptional or translational inhibition of StAR expression results in a dramatic decrease in steroid biosynthesis, whereas approximately $10 \%-15 \%$ of steroid synthesis appears to be mediated through StAR-independent mechanisms. ${ }^{74,75}$ In contrast, normal regulation of steroid production appears to be largely mediated by increased transcription of steroidogenic enzymes. ${ }^{76}$

\section{KER: decreased StAR levels lead to a reduction in cholesterol transport}

StAR mediates the delivery of cholesterol from the outer to the inner mitochondrial membrane, where it undergoes side chain cleavage by a cytochrome P-450 enzyme (P450scc) that yields the steroid precursor, pregnenolone. ${ }^{59}$ The cholesterol transfer within the mitochondria is the rate-limiting step in the production of steroid hormones (reviewed in Miller and Auchus ${ }^{77}$ ). Therefore, reduced amount/activity of the StAR will impair the cholesterol delivery necessary for the hormone biosynthesis. StAR is primarily present in steroid-producing cells, including theca cells and luteal cells in the ovary, Leydig cells in the testis, and some cell types in the adrenal cortex.

Downregulation of StAR and impaired steroidogenesis were reported on exposure to phthalates, ${ }^{49}$ and a correlation was observed between inhibition of steroidogenesis and reduction of cholesterol synthesis in the fetal testis, including total testis cholesterol levels. ${ }^{78}$ It is worth noting that some steroidogenesis is independent of StAR, however, the mechanism of StAR-independent steroidogenesis is unclear. $^{77}$ Johnson et al. ${ }^{82}$ also proposed the involvement of sterol regulatory element-binding protein (SREBP) in phthalatemediated disruption of steroidogenesis. Their study showed that lipid metabolism pathways transcriptionally regulated by SREBP were inhibited in the rat but induced in the 
mouse, and this differential species response corresponded with repression of the steroidogenic pathway.

\section{KE2: Reduction of Cholesterol Transport in Leydig Cells}

In mitochondria of steroidogenic tissues, there are two specialized mechanisms related to hormone synthesis: one by which cholesterol is delivered to the mitochondria and the other by which specialized intramitochondrial enzymes participate in the synthesis of hormonal steroids.

Steroidogenesis begins with the transport of cholesterol from intracellular stores into mitochondria. This process involves a series of protein-protein interactions involving cytosolic and mitochondrial proteins located at both the outer and inner mitochondrial membranes. In steroidogenic cells, cholesterol import to the mitochondrial inner membrane is crucial for steroid synthesis. ${ }^{79}$ This process is facilitated by the scavenger receptor class B type 1 (SR-B1; more relevant to rodents, than humans) that mediates the selective uptake of cholesterol esters from high-density lipoproteins. STAR and TSPO mediate the transport of cholesterol across the mitochondrial membrane.

The rate of formation of systemic steroid hormones depends on the rate of cholesterol transport from intracellular stores to the inner mitochondrial membrane and loading of P450scc with cholesterol. ${ }^{77}$ Interference with one or more of these reactions leads to reduced efficiency of steroid production.

\section{KER: reduction of cholesterol transport leads to a reduction of testosterone synthesis}

Production of steroid hormones depends on the availability of cholesterol in the mitochondrial matrix. Decreased cholesterol inside the mitochondria (e.g., by decreased expression of StAR or TSPO) leads to diminished substrate for hormone (testosterone) production.

Steroid hormones play a critical role in sexual development, homeostasis, stress responses, carbohydrate metabolism, and reproduction. Within steroidogenic tissues they are synthesized from a common precursor, cholesterol. Mitochondria are a key control point for the regulation of steroid hormone biosynthesis. The first and rate-limiting step in steroidogenesis is the transfer of cholesterol from the outer mitochondrial membrane to the inner mitochondrial membrane, a process dependent on the action of StAR.$^{56}$ The subsequent transport across the inner mitochondrial space into the steroidogenic pathway is executed by TSPO. ${ }^{80}$

Testosterone production by Leydig cells is primarily under the control of luteinizing hormone (LH). Stimulation of the Leydig cells results in the activation of StAR transcription and translation, facilitating the transfer of cholesterol into the mitochondrial matrix to P450scc (CYP11A), which converts cholesterol to pregnenolone. Pregnenolone diffuses to the smooth endoplasmic reticulum (ER) where it is further metabolized to testosterone via the actions of $3 \beta$ hydroxysteroid dehydrogenase $\Delta 5$ - $\Delta 4$-isomerase ( $3 \beta$-HSD), $17 \alpha$-hydroxylase/C17-20 lyase (P450c17, CYP17), and 17 $\beta$ hydroxysteroid dehydrogenase type III (17HSD3). For review, see Payne and Hales. ${ }^{81}$

Decreased expression of genes that are responsible for cholesterol transport and steroidogenic enzyme activity, in the Leydig cell, leads to decreased testosterone production.
There is evidence demonstrating a coordinated reduction in the expression of key genes and proteins involved in cholesterol transport and steroidogenesis, together with a corresponding reduction in testosterone in testes in response to phthalates. For example, exposure of rats to $500 \mathrm{mg} / \mathrm{kg}$ phthalate (DBP) caused a profound reduction in the expression of genes involved in lipid metabolism in fetal Leydig cells. ${ }^{82,83}$ Fetal Leydig cells normally exhibit a high rate of lipid metabolism, which is required for both synthesizing and importing the testosterone precursor cholesterol.

In addition, after phthalate exposure, testis cholesterol and cholesterol-containing lipid droplets in fetal Leydig cells are also reduced. ${ }^{51,78,82}$ Testosterone production may also be diminished due to reduction/inhibition of other genes than TSPO and StAR (e.g., P450scc). ${ }^{47,71}$

\section{KE3: Reduction of Testosterone Synthesis in Leydig Cells}

In humans and other mammals, testosterone is secreted primarily by the testes and, to a lesser extent, the ovaries. Small amounts are also secreted by the adrenal glands. Testosterone is synthesized by the gonads and other steroidogenic tissues (e.g., brain, adipose) acting locally or being transported to other tissues via blood circulation. Steroid synthesis takes place within the mitochondria of Leydig cells, the testosterone-producing cells of the testis.

Testosterone production depends on stimulation of these cells by LH that is secreted in pulses into the peripheral circulation by the pituitary gland in response to gonadotropinreleasing hormone $(\mathrm{GnRH})$ from the hypothalamus. Testosterone and its aromatized product, estradiol, then feed back to the hypothalamus and pituitary to suppress transiently $\mathrm{LH}$ and thus testosterone production. In response to reduced testosterone, GnRH and LH are again produced. This negative feedback cycle results in pulsatile secretion of LH followed by pulsatile production of testosterone. . $^{84,85}$

Testosterone is the principal male sex hormone and an anabolic steroid. Male sexual differentiation in general depends on testosterone, dihydrotestosterone, and the expression of androgen receptors (ARs) by target cells. ${ }^{86}$ During development, secretion of androgens by Leydig cells is essential for masculinization of the fetus. ${ }^{87}$

The fetal Leydig cells develop in utero. These cells become competent to produce testosterone in rat by GD 15.5, with production increasing markedly thereafter. Peak steroidogenic activity is reached just before birth, on GD 19. Testosterone secreted by fetal Leydig cells is required for the differentiation of the male urogenital system late in gestation. ${ }^{88}$ Fetal Leydig cells also play a role in the scrotal descent of the testis through their synthesis of insulin-like growth factor 3 (Insl3), for review, see Nef. ${ }^{87}$

In humans, the first morphological sign of testicular differentiation is the formation of testicular cords, which can be seen between 6 and 7 weeks of gestation. Steroid-secreting Leydig cells can be seen in the testis at 8 weeks of gestation. At this period, the concentration of androgens in the testicular tissue and blood starts to rise, peaking at 14-16 weeks of gestation. At this time, the number of Leydig cells also increases (for review, see Rouiller-Fabre et al. ${ }^{89}$ ).

Adult Leydig cells, which are distinct from the fetal Leydig cells, form during puberty and supply the testosterone 
required for the onset of spermatogenesis, among other functions. Distinct stages of adult Leydig cell development have been identified and characterized. The Leydig stem cells are undifferentiated cells that are not only capable of indefinite self-renewal but also of differentiation to steroidogenic cells. These cells give rise to progenitor Leydig cells, which proliferate, continue to differentiate, and give rise to the immature Leydig cells. The immature Leydig cells synthesize high levels of testosterone metabolites. The adult Leydig cells are terminally differentiated cells that are derived from immature Leydig cells. These cells are characterized by their production of high levels of testosterone. With aging, both serum and testicular testosterone concentrations progressively decline, for review see Nef. ${ }^{87}$

Androgens play a crucial role in the development and maintenance of male reproductive and sexual functions. Therefore, low levels of circulating androgens can cause disturbances in male sexual development, resulting in congenital abnormalities of the male reproductive tract. Later in life, this may cause reduced fertility, sexual dysfunction, decreased muscle formation and bone mineralization, disturbances of fat metabolism, and cognitive dysfunction. Testosterone levels decrease as part of the aging process: signs and symptoms caused by this decline can be considered a normal part of aging.

\section{KER: reduction of testosterone synthesis leads directly to reduction of testosterone levels}

Impairment of testosterone production in Leydig cells within the testes directly impacts on testosterone levels. The testosterone synthesized is used locally but also excreted into the circulation, causing reduced testosterone levels at other sites.

Rats administered DEHP or DINP during the gestational period showed a coordinated reduction in the production of testosterone followed by reduction of testosterone levels in fetal testes and in serum. ${ }^{49,90}$

\section{KE4: Reduction of Testosterone in the Testes}

Androgens (principally testosterone and $5 \alpha$-dihydrotestosterone) are critical for the development of the male phenotype during embryogenesis and for the achievement of sexual maturation at puberty. The decreased production and consequently reduced levels of testosterone in the fetal period lead to disrupted development of the male reproductive tract. In adulthood, androgens remain essential for the maintenance of male reproductive function and behavior. Apart from their effects on reproduction, androgens affect a wide variety of nonreproductive tissues such as skin, bone, muscle, and brain. ${ }^{91}$ Androgens exert most of their effects by interacting with the AR, for review see Murashima et al. ${ }^{92}$ Testosterone may be metabolized by $5 \alpha$-reductase to produce $5 \alpha$ dihydrotestosterone or aromatized to generate estrogens.

\section{KER: reduction of testosterone levels leads indirectly to male reproductive tract malformations}

Male sexual differentiation in general depends on levels of testosterone, dihydrotestosterone, and the expression of ARs by target cells. ${ }^{86}$ Disturbances in the balance of this endocrine system by either endogenous or exogenous factors may lead to male reproductive tract malformations (e.g., hypospadias, cryptorchidism).
Fetal androgens are crucial for the development of the male reproductive tract especially during the first trimester of pregnancy. Androgens regulate masculinization of external genitalia. Testosterone is necessary for stabilization and differentiation of the Wolffian structures (e.g., the epididymis, vas deferens, and seminal vesicles) and also for normal development of the fetal testes. Dihydrotestosterone, produced locally from testosterone, is required for normal development of the genital tubercle and urogenital sinus into the external genitalia and prostate. ${ }^{92}$ Therefore, any defects in androgen biosynthesis, metabolism, or action during development can cause hypospadias. ${ }^{93}$ Substances with antiandrogenic activity may alter the complex regulation of male sex differentiation during fetal life. ${ }^{94}$ Although the cause in most cases is unknown, hypospadias has been associated with aberrant androgen signaling during development. ${ }^{95}$

The etiology of this frequent malformation has not been elucidated despite intensive investigation. ${ }^{96}$ Hypospadias thus appears at the crossroads of genetic, endocrine, and environmental mechanisms. ${ }^{96}$

Reduced testosterone production during male rat development was seen after exposure of rats to di-butyl phthalate, ${ }^{19,21}$ butyl benzyl phthalate, and DEHP, ${ }^{20}$ this led to hypospadias in the newborn pups.

Epidemiological studies have demonstrated an association between fetal estrogen exposure and hypospadias. ${ }^{97,98}$ However, the molecular mechanism underlying this association is unknown. ${ }^{99,100}$ Maternal exposure to estrogenic and antiandrogenic endocrine disrupting compounds has been implicated in increased risk of cryptorchidism and hypospadias in human male offspring although the apparent association was not statistically significant. ${ }^{101}$

Reduction in testosterone levels during fetal development and subsequent lower levels of its metabolite dihydrotestosterone lead also to impaired growth of the perineum. ${ }^{102}$ This in turn may lead to reduced anogential distance (AGD). ${ }^{102}$ AGD is a sexual dimorphism that results from the sex difference in fetal androgen dihydrotestosterone levels. ${ }^{103}$ The AGD is a marker of perineal growth and caudal migration of the genital tubercle. It is androgen dependent in male rodents. ${ }^{102}$

During development, androgens stimulate the growth of the perineal region between the sex papilla and the anus, resulting in an increased AGD in male offspring. ${ }^{102}$ The AGD is believed to be a biomarker of prenatal androgen exposure in many species, and in humans it has been associated with several adverse reproductive health outcomes in adults. AGD reflects fetal androgen exposure only within a discrete masculinization programming window (MPW), during which development of male reproductive organs is taking place. ${ }^{95,104}$

Decreased AGD has also been associated with the perturbation of androgen-mediated development of the reproductive tract in rat males, which were exposed to antiandrogens in utero. ${ }^{95,105,106}$ Several studies have indicated that exposure to phthalates resulted in decreased AGD in human males, 107,108 presumably due to lowered testosterone levels. ${ }^{17,109,110}$

\section{A01: Male Reproductive Tract Malformation}

Male reproductive tract malformations (congenital malformation of male genitalia) comprise any physical abnormality of the male internal or external genitalia present at birth. Some result 
from excessive or deficient androgen concentrations, others result from teratogenic effects, or are associated with anomalies of other parts of the body in a recognizable pattern (i.e., a syndrome). The cause of many of these birth defects is unknown.

Malformations are detected macroscopically for any structural abnormality or pathological change. Congenital malformation of the genitalia is a medical term referring to a broad category of conditions for humans, classified by the International Classification of Diseases (ICD) in the chapter "Congenital malformations of genital organs" (Q50-Q56), for example, Q54 Hypospadias, Q53 Undescended testicle. Hypospadias is usually diagnosed during the routine examination after birth and is within the category of "Congenital malformation of the genitalia." Hypospadias is a malformation in which the urethra opens on the underside of the penis instead of the tip. It results from an incomplete closure of the urethral folds, leaving a split on the penis. ${ }^{96}$ When the urethra opens to the glans or corona of the penis, it is called distal, whereas opening to the shaft or penoscrotal area defines hypospadias as proximal.

Androgens regulate the masculinization of external genitalia. Therefore, any defects in androgen biosynthesis, metabolism, or action during fetal development can cause hypospadias. Gene defects causing disorders of testicular differentiation, conversion of testosterone to dihydrotestosterone, or mutations in the AR can also result in hypospadias. ${ }^{94}$ In about $20 \%$ of patients with isolated hypospadias, there are signs of endocrine abnormalities by the time of diagnosis. ${ }^{93}$ The majority of hypospadias is believed to have a multifactorial etiology, although a small percentage results from singlegene mutations. ${ }^{111}$ The only treatment of hypospadias is surgery, and thus, prevention is imperative.

The AGD is the distance from the anus to the genitals and the male/female differences result from the sex difference in fetal androgen (DHT) levels. ${ }^{103}$ The AGD is widely used as biomarker of prenatal androgen exposure during a reproductive programming window. ${ }^{95,104,106}$ The AGD is a marker of perineal growth and caudal migration of the genital tubercle. It is androgen dependent in male rodents. ${ }^{102}$ Measurement of AGD has also been proposed as a quantitative biomarker of fetal ED exposure in humans. ${ }^{112,113}$

Across numerous species, including humans, AGD is longer in males compared to females; for review see Barrett et al. ${ }^{114}$ In males, a longer (more "masculine") AGD is typically associated with favorable health outcomes, while a shorter AGD is associated with adverse health outcomes. The AGD in males is approximately double that of females. Less is known about clinical correlates of AGD in females, although one study found that in women a longer AGD was associated with increased odds of multifollicular ovaries. ${ }^{115}$ AGD reflects the prenatal hormonal milieu and is a biomarker for the risk of reproductive health problems linked to that early hormonal environment. ${ }^{114}$ In animal studies, AGD measured from the genital tubercle to the anus is a sensitive marker of in utero exposure to androgens and antiandrogens, and is used extensively in animal reproductive toxicology studies. ${ }^{106}$ Decreased AGD in male rats is a hallmark of exposure to antiandrogenic substances. ${ }^{116}$ A statistically significant change in AGD that cannot be explained by the size of the animal indicates an adverse effect of exposure and should be considered in setting the no-observed-adverseeffect-level (NOAEL). ${ }^{117}$

\section{KER: male reproductive tract malformation} leads directly to impaired fertility

Impairment of the normal development of the male reproductive tract (e.g., genital abnormality and/or cryptorchidism) can impact on fertility later in life.

Hypospadias, followed by cryptorchidism, belongs to the most common male reproductive disorders that manifest at birth and may have a common origin in fetal life. ${ }^{118}$ They are also associated with decreased fertility. ${ }^{119}$ AGD reduction has also been associated with testicular dysfunction. ${ }^{120}$ A study by Asklund et al. showed that semen quality was reduced in men with hypospadias and additional genital disorders, predominately cryptorchidism. ${ }^{121}$ In another study by Bracka, $25 \%$ of 41 hypospadias patients, including 26 patients also with cryptorchidism, had a lower sperm density. ${ }^{122}$

Men with a history of cryptorchidism have an increased risk of infertility. ${ }^{119}$ Mendiola et al. examined healthy volunteers and found a positive relationship between semen parameters and anogenital distance. ${ }^{123}$ Eisenberg et al. found shorter AGD among infertile men compared with fertile men. ${ }^{120}$

In rodents, in utero exposure to substances (including phthalates) known to disrupt androgen-mediated pathways disrupts normal male genital development resulting in a decrease in genital length (i.e., phallus length, AGD) and impaired testosterone and sperm production. ${ }^{102,124,125}$

\section{A02: Impaired Fertility}

Fertility is the capacity to conceive or induce conception. Impairment of fertility represents disorders of male or female reproductive functions or capacity. Fertility rate is measured by the number of offspring born per mating pair, expressed as individuals or populations.

\section{Overall Assessment of the AOP}

In the presented AOP, it is hypothesized that the KEs occur in a biologically plausible order before the development of AOs. The PPAR $\alpha$ activators have been shown to alter steroidogenesis and impair reproduction (see reviews David, ${ }^{8}$ Latini et al., ${ }^{10}$ and Corton and Lapinska ${ }^{35}$ ). The biochemistry of steroidogenesis and the predominant role of the gonad in synthesis of the sex steroids are well established. Steroidogenesis is a complex process that is dependent on the availability of cholesterol in mitochondria. Perturbation of genes responsible for cholesterol transport and steroidogenic enzyme activities in the Leydig cell may lead to a decrease in testicular testosterone production. As a consequence, androgen-dependent tissue differentiation and development will be adversely affected. The physical manifestation of this event may be reproductive tract malformation, which may possibly lead to impaired fertility.

This is a qualitative description of the pathway; the currently available studies only provide partial quantitative information on dose-response relationships. Experimental data are based on exposure to phthalates and indicate that KEs of this pathway occur at similar dose levels. Effects on the expression levels of genes that are responsible for the cholesterol transport into the Leydig cells were shown at $>50 \mathrm{mg} / \mathrm{kg} / \mathrm{bw}$, a dose at which fetal testosterone was decreased and anatomical malformations (hypospadias) were produced. ${ }^{19,51,126,127}$

Currently, a more comprehensive quantitative assessment of the KERs in this AOP is not possible due to limited data. 


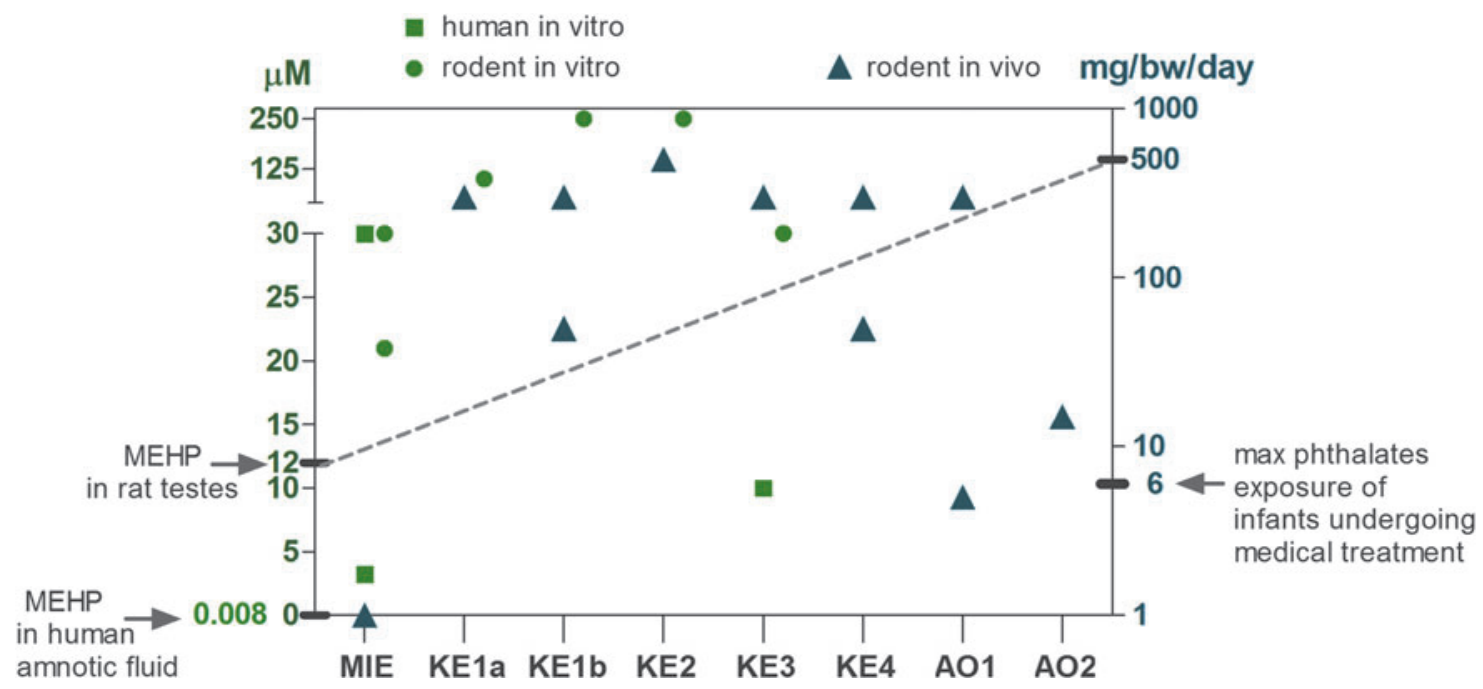

FIG. 2. Illustration of quantitative data for described AOP. Doses/concentrations at which positive results for the KEs are shown. Green circles represent rodent - in vitro data, green squares-in vitro human, and blue triangles represent rat in vivo data. The points correspond to $\mathrm{MIE}$ (MEHP: $\mathrm{EC}_{50}=3.2 \mu \mathrm{M}$, in vitro human cells, ${ }^{161} \mathrm{DBP}: \mathrm{EC}_{50}=30 \mu \mathrm{M}$ in vitro human cells, ${ }^{161} \mathrm{DBP}: \mathrm{EC}_{50}=21 \mu \mathrm{M}$ in vitro rodent cells, ${ }^{161} \mathrm{MEHP}: \mathrm{LOEC}=30 \mu \mathrm{M},{ }^{162} \mathrm{DEHP}=1 \mathrm{mg} / \mathrm{kg} / \mathrm{day}$ in vivo rodent), $\mathrm{KE} 1 \mathrm{a}$ (DBP:LOEC $=100 \mu \mathrm{M}$ in vitro, MA-10 Leydig cells, ${ }^{45} \mathrm{DEHP}: \mathrm{LOEC}=300 \mathrm{mg} / \mathrm{kg} / \mathrm{day}$ in vivo $\left.\mathrm{rat}^{49}\right), \mathrm{KE} 1 \mathrm{~b}(\mathrm{MEHP}: \mathrm{LOEC}=$ $250 \mu \mathrm{M}$ in vitro rat, ${ }^{163}$ DEHP: LOEL $=300 \mathrm{mg} / \mathrm{kg} /$ day in vivo rat, ${ }^{49} \mathrm{DBP}: \mathrm{LOEL}=300 \mathrm{mg} / \mathrm{kg} / \mathrm{day}$ in vivo rat $\left.{ }^{78}\right), \mathrm{KE} 2(\mathrm{DBP}$ : $\mathrm{LOEL}=500 \mathrm{mg} / \mathrm{kg} /$ day in vivo $\mathrm{rat}^{78}$ ), KE3 (MEHP:LOEC $=10 \mu \mathrm{M}$ in vitro inhibition of testosterone production in human testicular explants, ${ }_{164} \mathrm{DBP}: \mathrm{LOEL}=500 \mathrm{mg} / \mathrm{kg} / \mathrm{day}$ in vivo $\left.\mathrm{rat}^{78}\right), \mathrm{KE} 4\left(\mathrm{DBP}: \mathrm{LOEL}=50 \mathrm{mg} / \mathrm{kg} / \mathrm{day}\right.$ in vivo rat, ${ }^{165} \mathrm{DEHP}$ : $\mathrm{LOEL}=300 \mathrm{mg} / \mathrm{kg} / \mathrm{day}$ in vivo $\mathrm{rat}^{90}$ ), AO1 (DEHP: LOEL $=5 \mathrm{mg} / \mathrm{kg} / \mathrm{day}$ in vivo $\mathrm{rat}^{166} \mathrm{DEHP}: \mathrm{LOEL}=50 \mathrm{mg} / \mathrm{kg} / \mathrm{day}$ in vivo rat, ${ }^{167}$ ) AO2 (DEHP: LOEL $=5 \mathrm{mg} / \mathrm{kg} /$ day in vivo rat, ${ }^{168} \mathrm{DEHP}:$ LOEL $=15 \mathrm{mg} / \mathrm{kg} / \mathrm{day}$ in vivo rat ${ }^{166}$ ). The mean testes concentrations of MEHP $(12 \mu \mathrm{M})$ after an administered dose of $500 \mathrm{mg} / \mathrm{kg} /$ day in vivo to rats ${ }^{169}$ are shown on the figure (dotted line). The concentration of MEHP in human amniotic fluid $(0.0082 \mu \mathrm{M})^{156}$ and the maximal exposure concentration of phthalates for infants undergoing medical treatment ${ }^{125}$ are also shown. AOP, adverse outcome pathway; DBP, dibutyl phthalate; KE, key event; MEHP, mono(2-ethylhexyl) phthalate.

Figure 2 illustrates the available experimental data providing starting point for designing tailored experiments to further support the pathway. It can be seen that the data derive from different experimental conditions and measured endpoints and therefore are not intended to provide quantification of the dose-response relationships. The paucity of data shows the need for tailored experiments to interrogate this AOP further, that is, dose-response relationships between the KEs.

The AOs are results of the chemical exposure during a critical prenatal period of male development, the MPW, within which androgens must act to ensure the correct development of the male reproductive tract. ${ }^{128}$ Therefore, the AOP focuses on the exposures within the MPW (15.5-18.5 GD days in rats).

The temporal relationship of exposure to GD has been investigated using phthalates and it has been demonstrated that the gestational timing of exposure is important for the production of adverse effects on the male reproductive tract (reviewed in $\mathrm{Ema}^{129}$ ). Moreover, the temporal relationship between alterations of gene expression and changes in testosterone production has been investigated for phthalates (DBP). ${ }^{51,83}$ Initial increases in the expression of genes, which are associated with steroidogenesis, are followed by decreases in gene expression of the same genes. The observed decreased steroidogenesis and subsequent decrease in testosterone levels is a well-established precursor to anatomical changes in the developing male reproductive tract. Thus, those KEs of gene expression are temporally consistent with subsequent events, however, complete temporal concordance studies are missing.
The strength of the chosen chemical initiators as PPAR $\alpha$ activators was shown to partially correlate with their ability to act as male reproductive toxicants. ${ }^{35}$ The presented KEs leading to a decrease in steroidogenesis are plausible and consistent with the observed effects. There is also coherence between decreased testosterone synthesis and malformations.

\section{Uncertainties, inconsistencies}

The major uncertainty in this AOP is the functional relationship between the MIE: PPAR $\alpha$ - activation and reduction of cholesterol transport (KE1a and KE1b): possible mechanisms have been proposed and investigated, however, dose-response data to support this relationship are lacking.

Studies exploring the role of $\operatorname{PPAR} \alpha$ using $\operatorname{PPAR} \alpha$ knockout mice showed that prenatal exposure to phthalates caused developmental malformations in both wild-type and $\operatorname{PPAR} \alpha$ knockout mice, thus suggesting a PPAR $\alpha$ independent mechanism. However, it is difficult to draw any conclusion on the role of PPAR $\alpha$ in phthalate-related reproductive toxicity in this study since the intrauterine administration of phthalate (DEHP) occurred before the critical period of reproductive tract differentiation; moreover, the doses were high and caused maternal toxicity. ${ }^{130}$ Intrauterine DEHP-treated PPAR $\alpha$-deficient mice developed delayed testicular, renal, and developmental toxicities, but no liver toxicity, compared to wild types, thus confirming the early observation by Lee et al. about the PPAR $\alpha$ dependence of liver response ${ }^{131}$ and, more importantly, indicating 
that DEHP may induce reproductive toxicity through both PPAR $\alpha$-dependent and PPAR $\alpha$-independent mechanisms. ${ }^{48}$

PPAR $\alpha$-independent reproductive toxicity observed by Ward et al. may conceivably be mediated by other PPAR isoforms, ${ }^{48}$ such as $\operatorname{PPAR} \beta$ and $\operatorname{PPAR} \gamma$, or by a nonreceptor-mediated organ-specific mechanism. ${ }^{132}$ Other studies showed that the administration of DEHP resulted in less severe testis lesions and higher testosterone levels in PPAR $\alpha$-null mice than in wildtype mice. ${ }^{45} \mathrm{~A}$ more recent report, investigating the role of $\operatorname{PPAR} \alpha$, showed decreased testosterone levels in PPAR $\alpha(-/-)$ null control mice, suggesting a positive constitutive role for PPAR $\alpha$ in maintaining Leydig cell steroid formation. ${ }^{18}$

\section{Alternative mechanism(s) or MIE(s) described, which may contribute to or synergize with the postulated AOP}

The inhibitory effect of PPAR $\alpha$ activation seems to be attributable to an impairment of the multistep process of cholesterol mobilization, transport into mitochondria, and steroidogenesis leading to impaired androgen production. Therefore, it is plausible that several other mechanisms may contribute to or synergize with this AOP. For example, activation of other isoforms of PPARs (PPAR $\beta / \delta$ or/and $\gamma)$ is hypothesized to be relevant for the pathway. ${ }^{133,134}$

Opposing effects of PPAR $\gamma$ ligands (thiazolidinediones, TZD) on androgen levels and/or production in male humans $^{135-137}$ and animal models have been described. ${ }^{138-144}$ In rats no effects of the PPAR $\gamma$ ligand (rosiglitazone) on total circulating testosterone levels were seen in one study, ${ }^{47}$ however, in another study a decrease in basal or induced testosterone production occurred in the Leydig cells of rosiglitazonetreated rats. ${ }^{145}$ Confusingly, there are also contradicting reports as to the presence of PPAR $\gamma$ in the fetal testes. ${ }^{50}$

Another mechanism leading to decreased fertility implicating the activation of PPARs may also be increased FA oxidation, and reduced capacity to cope with increased oxidative stress. $^{145}$

The involvement of epigenetics is also hypothesized. Changes in methylation patterns may be, in part, mediated by the PPAR pathway. DEHP affected the epigenome at doses from $1 \mathrm{mg} / \mathrm{kg} /$ day, doses that are relevant for human exposure. Epigenetic changes were observed in animals exposed to DEHP only during the fetal period, yet effects on steroid hormone levels were observed in adults. Moreover, the data suggest that high levels of DEHP affected key loci and deregulated gene expression beyond a point of compensation. $^{147,148}$

\section{Discussion}

Endocrine disruption is an important health and policy issue with high priority for regulatory authorities globally. Environmental exposures to chemicals with endocrine disrupting properties may interfere with fertility in both male and female. Infertility, a disease characterized by the inability to have a child, affects one in six couples and will likely rise as the postponement of childbearing increases in developed regions of the world. ${ }^{149}$ The associated healthcare cost of infertility is billions of dollars per year and does not include the tremendous physical and psychological burden for the couples. This highlights the public health importance of understanding risk factors that are connected with reproductive and developmental toxicity.
Adverse effects on the reproductive system may be induced directly, especially in adult males by damaging the semen producing epithelium or indirectly by interfering with sex hormone homeostasis. These processes might be disturbed by interfering agents (e.g., by antiandrogens), provided that the level of exposure is high enough. Effects on the reproductive system may involve perturbation of many biological pathways where critical events occur during well-defined periods of prenatal and early postnatal development. In the male, sexual differentiation depends on the presence of androgens during the male programming window and lack of this "imprinting" will result in irreversible defects or dysfunctions.

Human and experimental animal studies identify several classes of chemicals that adversely impact fertility and pregnancy. One class of environmental chemicals for which there is concern related to the risk of adverse reproductive and developmental effects are the phthalates. Human exposure to phthalates is widespread and occurs through multiple routes, including ingestion, inhalation, dermal contact, and parenteral exposure from medical devices containing phthalates. ${ }^{150}$

Existing human data on phthalates concerning possible developmental effects derive from prospective epidemiological studies, lately reviewed by Lioy et al. ${ }^{151}$ They are focused on association of maternal phthalate exposure with male reproductive tract developmental endpoints. The measurements of phthalate metabolites in the amniotic fluid would provide the best estimate of the actual internal dose for the fetus, taken during weeks 15-20 of fetal development (sensitive window). These measurements are, however, difficult to obtain and may pose some risk to the fetus, moreover, amniotic fluid has a continuous turn over. There are only few published studies on human amniotic fluid levels of phthalate metabolites. ${ }^{12,152,153}$ Therefore, maternal urinary levels may be the most appropriate surrogate of both maternal and fetal phthalate exposure. ${ }^{152,153}$

Reduced AGD has been reported in male infants in relation to higher maternal urinary concentrations of DEHP metabolites. ${ }^{17,107,154}$ The study by Huang et al. ${ }^{155}$ also found similar associations of monoethyl phthalate and mono butyl phthalate with reduced AGD. This study did not find associations of any phthalate metabolite with reduced AGD in boys, but did so in girls.

Shortened AGD in males is regarded as a biomarker of insufficient androgen action in fetal life, ${ }^{156}$ and there are relationships with other male reproductive disorders that are similar to those observed in rats with the phthalate syndrome. Thus, Hsieh et al. reported that boys with hypospadias had shorter AGD than boys with normal genitals. ${ }^{157}$ Shorter AGD was associated with poorer semen quality ${ }^{123}$ and infertility. ${ }^{120}$ In addition, semen quality was reduced in men with hypospadias $^{122}$ and additional genital disorders, predominately cryptorchidism, ${ }^{121}$ and men with a history of cryptorchidism have an increased risk of infertility. ${ }^{119}$

In rodents, in utero exposure to agents known to disrupt androgen-mediated pathways disrupts normal male genital development with a decrease in genital length (phallus length, AGD) and impaired testosterone and sperm production, ${ }^{104,124}$ including exposure to phthalates. ${ }^{125}$ Despite many years of research on phthalates, there is no scientifically agreed and established MoA of these chemicals for male reproductive toxicity. The exact molecular mechanism for the action of phthalates remains to be elucidated. 
The presented AOP describes the scientific evidence and highlights data gaps. The major uncertainty in this AOP lies in the functional relationship between (MIE) PPAR $\alpha$ and impaired cholesterol synthesis. Complete/pathway-driven studies to investigate the effects of PPARs and their role in male reproductive development are lacking. For establishing a solid quantitative and temporal coherent linkage, an MoA framework analysis for PPAR $\alpha$-mediated developmental toxicity is needed.

This approach has been applied for the involvement of PPAR $\alpha$ in liver toxicity. ${ }^{158,159}$ The mechanistic basis for phthalate action needs structured well-designed experiments to further elucidate and substantiate the pathways and such experimental approaches may then be used to facilitate development of predictive models to be applied to other chemicals to evaluate if they have the potential to operate via a similar MoA.

Reproductive toxicity testing according to the present guidelines requires a high number of test animals. No single in vitro assay possesses the predictive power to identify reproductive toxicants to date. Therefore, structured approaches gathering relevant information across different types of studies can drive assessment in this field, describing connections and incorporating plausible mechanisms. Once the AOP is fully established and quantitative relationships are understood, then it may be possible to use in vitro mechanistic studies to help predict the adverse effects.

\section{Future Perspectives and Conclusions}

This AOP adds to the AOP network by mapping to MoAs for endocrine disruption other than via such well-established mechanisms of ER, AR (ant)agonism, and aromatase inhibition. It provides a framework supporting understanding of the mechanisms and the evidence for plausibility of the MoA through a combination of non/-testing approaches that can be practically integrated and used to support regulatory decisions. The AOP, along with other ED-relevant AOPs in the AOP-Wiki, was suggested to be used to support a plausible link between the available mechanistic data and the adverse effects in the screening methodology for identification of endocrine disrupters carried out in the context of a European Commission impact assessment on options for criteria to identify EDs ${ }^{160}$ because it was considered that the pathway provides a basis for linking an endocrine MoA with an adverse effect, a prerequisite requirement for identification of endocrine disrupting chemicals (EDCs) according to the WHO definition. ${ }^{2}$ Moreover, the AOP could inform the development of quantitative structure/activity relationships, r-ad-across models, and/or systems biology models to prioritize chemicals for further reproductive/developmental toxicity testing.

The current AOP framework uses a simplified depiction of a linear progression of events across levels of biological organization that translate a molecular perturbation to an AO. However, it is well recognized that AOPs actually operate as networks within a systems biology context and that various AOPs can share KEs and pathways may converge and lead to a variety of different outcomes within the umbrella term of reproductive toxicity.

Ultimately, understanding of responses to stressors to be able to effectively predict toxicity, in a systems biology context that operates across multiple levels of biological organization, will require the kind of network thinking that new approaches investigating interactions at the molecular and cellular level promote. As indicated substances may act on more than one MIE, it may be the combination of these interactions that is required to invoke a described AO. Further research is required to elucidate more precisely the MIE or MIEs that may lead to a decrease in steroidogenesis; however, it may not be necessary to establish a specific MIE to find a regulatory use for an AOP. Focusing on assay development for converging KEs in an AOP network may be one relevant use case not requiring knowledge of the individual MIEs.

AOP development is facilitated by the AOP knowledgebaseproviding a platform for interdisciplinary teamwork between the scientists, facilitating the development of AOP networks. The success of the undertaking relies on the joint efforts of many researchers from various disciplines, including toxicology, biology, chemistry, clinical medicine, and computer modeling. Increasing contribution from AOP developers adding and connecting their AOPs through common KEs to build AOP networks will eventually better represent the complex biological processes and interactions in response to various chemical exposures.

The pathway-based approaches have the aim of improving the science of human and environmental safety assessment while ultimately reducing the reliance on animal toxicity testing. Many technical challenges still remain to be solved before this vision is realized. Central to these challenges is the need for AOPs to produce a quantitative output (i.e., response-response relationships). By structurally representing current knowledge of the pathway from PPAR $\alpha$ activation to impaired fertility, this AOP may provide a basis for development (and interpretation) of strategies for Integrated Approaches to Testing and Assessment (IATA) to identify similar substances that may operate via the same MoA and lays a strong foundation for the development of other AOPs within the context of an AOP network.

\section{Author Disclosure Statement}

No competing financial interests exist.

\section{References}

1. Kortenkamp AA, Martin O, Faust M, et al. State of the art assessment of endocrine disrupters. Final Report Project Contract Number 070307/2009/550687/SER/D3; 2011.

2. WHO/IPCS. Global Assessment of the State-of-the-Science of Endocrine Disruptors. Geneva: World Health Organization/International Programme on Chemical Safety; 2002.

3. OECD. Guidance Document on Standardised Test Guidelines for Evaluating Chemicals for Endocrine Disruption. Paris: Organisation for Economic Co-operation and Development, 2012, p. 524.

4. Ankley GT, Bennett RS, Erickson RJ, et al. Adverse outcome pathways: A conceptual framework to support ecotoxicology research and risk assessment. Environ Toxicol Chem 2010:29;730-741.

5. OECD. Guidance document on developing and assessing adverse outcome pathways. IOMC/OECD 2013:184;45.

6. OECD. Lists of projects on the AOP development programme workplan - OECD. www.oecd.org/chemicalsafety/ 
testing/listsofprojectsontheaopdevelopmentprogramme workplan.htm (last accessed Apr. 10, 2017).

7. Howdeshell KL, Rider CV, Wilson VS, et al. Dose addition models based on biologically relevant reductions in fetal testosterone accurately predict postnatal reproductive tract alterations by a phthalate mixture in rats. Toxicol Sci 2015:148;488-502.

8. David R. Proposed mode of action for in utero effects of some phthalate esters on the developing male reproductive tract. Toxicol Pathol 2006:34;209-219.

9. OECD. Users' handbook supplement to the guidance document for developing and assessing adverse outcome pathways. Paris: Organisation for Economic Co-operation and Development, 2016 [Epub ahead of print]; doi:10.1787/ 5 jlv1m9d1g32-en

10. Latini G, Scoditti E, Verrotti A, et al. Peroxisome proliferatoractivated receptors as mediators of phthalate-induced effects in the male and female reproductive tract: Epidemiological and experimental evidence. PPAR Res 2008:2008;359267.

11. Heudorf U, Mersch-Sundermann V, Angerer J. Phthalates: Toxicology and exposure. Int J Hyg Environ Health 2007: 210;623-634.

12. Silva MJ, Barr DB, Reidy JA, et al. Urinary levels of seven phthalate metabolites in the U.S. population from the National Health and Nutrition Examination Survey (NHANES) 1999-2000. Environ Health Perspect 2004: 112;331-338.

13. Wittassek M, Heger W, Koch HM, et al. Daily intake of di(2-ethylhexyl)phthalate (DEHP) by German childrenA comparison of two estimation models based on urinary DEHP metabolite levels. Int J Hyg Environ Health 2007: 210;35-42.

14. Duty SM, Silva MJ, Barr DB, et al. Phthalate exposure and human semen parameters. Epidemiology 2003:14;269277.

15. Hauser R, Meeker JD, Duty S, et al. Altered semen quality in relation to urinary concentrations of phthalate monoester and oxidative metabolites. Epidemiology 2006:17; 682-691.

16. Stahlhut RW, van Wijngaarden E, Dye TD, et al. Concentrations of urinary phthalate metabolites are associated with increased waist circumference and insulin resistance in adult U.S. males. Environ Health Perspect 2007:115; 876-882.

17. Swan SH, Main KM, Liu F, et al. Decrease in anogenital distance among male infants with prenatal phthalate exposure. Environ Health Perspect 2005:113;1056-1061.

18. Borch J, Axelstad M, Vinggaard AM, et al. Diisobutyl phthalate has comparable anti-androgenic effects to di-nbutyl phthalate in fetal rat testis. Toxicol Lett 2006:163; 183-190.

19. Mylchreest E. Dose-dependent alterations in androgenregulated male reproductive development in rats exposed to di(n-butyl) phthalate during late gestation. Toxicol Sci 2000:55;143-151.

20. Gray LE, Ostby J, Furr J, et al. Perinatal exposure to the phthalates DEHP, BBP, and DINP, but not DEP, DMP, or DOTP, alters sexual differentiation of the male rat. Toxicol Sci 2000:58;350-365.

21. Parks LG. The plasticizer diethylhexyl phthalate induces malformations by decreasing fetal testosterone synthesis during sexual differentiation in the male rat. Toxicol Sci 2000:58;339-349.
22. Wilson VS, Lambright C, Furr J, et al. Phthalate esterinduced gubernacular lesions are associated with reduced ins13 gene expression in the fetal rat testis. Toxicol Lett 2004:146;207-215.

23. Tyl RW, Myers CB, Marr MC, et al. Reproductive toxicity evaluation of dietary butyl benzyl phthalate (BBP) in rats. Reprod Toxicol 2004:18;241-264.

24. Hannas BR, Lambright CS, Furr J, et al. Dose-response assessment of fetal testosterone production and gene expression levels in rat testes following in utero exposure to diethylhexyl phthalate, diisobutyl phthalate, diisoheptyl phthalate, and diisononyl phthalate. Toxicol Sci 2011: $123 ; 206-216$.

25. Howdeshell KL, Furr J, Lambright CR, et al. Cumulative effects of dibutyl phthalate and diethylhexyl phthalate on male rat reproductive tract development: Altered fetal steroid hormones and genes. Toxicol Sci 2007:99;190-202.

26. Howdeshell KL, Rider CV, Wilson VS, et al. Mechanisms of action of phthalate esters, individually and in combination, to induce abnormal reproductive development in male laboratory rats. Environ Res 2008:108;168-176.

27. Albert O, Jegou B. A critical assessment of the endocrine susceptibility of the human testis to phthalates from fetal life to adulthood. Hum Reprod Update 2014:20;231-249.

28. Zarean M, Keikha M, Poursafa P, et al. A systematic review on the adverse health effects of di-2-ethylhexyl phthalate. Environ Sci Pollut Res Int 2016. doi:10.1007/ s11356-016-7648-3

29. Michalik L, Auwerx J, Berger JP, et al. International Union of Pharmacology. LXI. Peroxisome proliferator-activated receptors. Pharmacol Rev 2006:58;726-741.

30. Mukherjee R, Jow L, Croston GE, et al. Identification, characterization, and tissue distribution of human peroxisome proliferator-activated receptor (PPAR) isoforms PPARgamma2 versus PPARgamma1 and activation with retinoid $\mathrm{X}$ receptor agonists and antagonists. J Biol Chem 1997:272; 8071-8076.

31. Schultz R, Yan W, Toppari J, et al. Expression of peroxisome proliferator-activated receptor alpha messenger ribonucleic acid and protein in human and rat testis. Endocrinology 1999:140;2968-2975.

32. Wahli W, Desvergne B. Peroxisome proliferator-activated receptors: Nuclear control of metabolism. Endocr Rev 1999:20;649-688.

33. Evans RM, Barish GD, Wang Y. PPARs and the complex journey to obesity. Nat Med 2004:10;355-361.

34. Yessoufou A, Wahli W. Multifaceted roles of peroxisome proliferator-activated receptors (PPARs) at the cellular and whole organism levels. Swiss Med Wkly 2010:140; w13071.

35. Corton JC, Lapinskas PJ. Peroxisome proliferatoractivated receptors: Mediators of phthalate ester-induced effects in the male reproductive tract? Toxicol Sci 2004: 83;4-17.

36. Martin MT, Knudsen TB, Reif DM, et al. Predictive model of rat reproductive toxicity from ToxCast high throughput screening. Biol Reprod 2011:85;327-339.

37. Casals-Casas C, Feige JN, Desvergne B. Interference of pollutants with PPARs: Endocrine disruption meets metabolism. Int J Obes (Lond) 2008:32 Suppl 6;S53-S61.

38. Rotman N, Haftek-Terreau Z, Lücke S, et al. PPAR disruption: Cellular mechanisms and physiological consequences. CHIMIA Int J Chem 2008:62;340-344. 
39. Bhattacharya N, Dufour JM, Vo M-N, et al. Differential effects of phthalates on the testis and the liver. Biol Reprod 2005:72;745-754.

40. Sarath Josh MK, Pradeep S, Vijayalekshmi Amma KS, et al. Phthalates efficiently bind to human peroxisome proliferator activated receptor and retinoid $\mathrm{X}$ receptor $\alpha, \beta, \gamma$ subtypes: An in silico approach. J Appl Toxicol 2014:34; 754-765.

41. Gely-Pernot A, Raverdeau M, Célébi C, et al. Spermatogonia differentiation requires retinoic acid receptor $\gamma$. Endocrinology 2012:153;438-449.

42. Wagner MS, Wajner SM, Maia AL. Is there a role for thyroid hormone on spermatogenesis? Microsc Res Tech 2009:72;796-808.

43. Corton JC. Peroxisome proliferator-activated receptors: Mediators of phthalate ester-induced effects in the male reproductive tract? Toxicol Sci 2004:83;4-17.

44. Xie Y, Yang Q, DePierre JW. The effects of peroxisome proliferators on global lipid homeostasis and the possible significance of these effects to other responses to these xenobiotics: An hypothesis. Ann N Y Acad Sci 2002: 973;17-25.

45. Gazouli M. Effect of Peroxisome proliferators on Leydig cell peripheral-type benzodiazepine receptor gene expression, hormone-stimulated cholesterol transport, and steroidogenesis: Role of the peroxisome proliferator-activator receptor. Endocrinology 2002:143;2571-2583.

46. Campioli E, Batarseh A, Li J, et al. The endocrine disruptor mono-(2-ethylhexyl) phthalate affects the differentiation of human liposarcoma cells (SW 872). PLoS One 2011:6; e28750.

47. Boberg J, Metzdorff S, Wortziger R, et al. Impact of diisobutyl phthalate and other PPAR agonists on steroidogenesis and plasma insulin and leptin levels in fetal rats. Toxicology 2008:250;75-81.

48. Ward JM, Peters JM, Perella CM, et al. Receptor and nonreceptor-mediated organ-specific toxicity of $\mathrm{di}(2-$ ethylhexyl)phthalate (DEHP) in peroxisome proliferatoractivated receptor alpha-null mice. Toxicol Pathol 1998: 26;240-246.

49. Borch J, Metzdorff SB, Vinggaard AM, et al. Mechanisms underlying the anti-androgenic effects of diethylhexyl phthalate in fetal rat testis. Toxicology 2006:223;144-155.

50. Hannas BR, Lambright CS, Furr J, et al. Genomic biomarkers of phthalate-induced male reproductive developmental toxicity: A targeted RT-PCR array approach for defining relative potency. Toxicol Sci 2012:125;544-557.

51. Lehmann KP, Phillips S, Sar M, et al. Dose-dependent alterations in gene expression and testosterone synthesis in the fetal testes of male rats exposed to di (n-butyl) phthalate. Toxicol Sci 2004:81;60-68.

52. Plummer S, Sharpe RM, Hallmark N, et al. Timedependent and compartment-specific effects of in utero exposure to Di(n-butyl) phthalate on gene/protein expression in the fetal rat testis as revealed by transcription profiling and laser capture microdissection. Toxicol Sci 2007:97; 520-532.

53. Plummer SM, Dan D, Quinney J, et al. Identification of transcription factors and coactivators affected by dibutylphthalate interactions in fetal rat testes. Toxicol Sci 2013:132;443-457.

54. McCampbell A. CREB-binding protein sequestration by expanded polyglutamine. Hum Mol Genet 2000:9;21972202.
55. Sugawara T, Holt JA, Kiriakidou M, et al. Steroidogenic factor 1-dependent promoter activity of the human steroidogenic acute regulatory protein (StAR) gene. Biochemistry 1996:35;9052-9059.

56. Stocco DM. StAR protein and the regulation of steroid hormone biosynthesis. Annu Rev Physiol 2001:63; 193-213.

57. Liu K, Lehmann KP, Sar M, et al. Gene expression profiling following in utero exposure to phthalate esters reveals new gene targets in the etiology of testicular dysgenesis. Biol Reprod 2005:73;180-192.

58. Toda K, Okada T, Miyaura C, et al. Fenofibrate, a ligand for PPARalpha, inhibits aromatase cytochrome P450 expression in the ovary of mouse. J Lipid Res 2003:44; 265-270.

59. Besman MJ, Yanagibashi K, Lee TD, et al. Identification of des-(Gly-Ile)-endozepine as an effector of corticotropindependent adrenal steroidogenesis: Stimulation of cholesterol delivery is mediated by the peripheral benzodiazepine receptor. Proc Natl Acad Sci U S A 1989:86;4897-4901.

60. Yeliseev AA, Krueger KE, Kaplan S. A mammalian mitochondrial drug receptor functions as a bacterial "oxygen" sensor. Proc Natl Acad Sci U S A 1997:94;51015106.

61. Zisterer DM, Williams DC. Peripheral-type benzodiazepine receptors. Gen Pharmacol 1997:29;305-314.

62. Anholt RR, De Souza EB, Oster-Granite ML, et al. Peripheral-type benzodiazepine receptors: Autoradiographic localization in whole-body sections of neonatal rats. J Pharmacol Exp Ther 1985:233;517-526.

63. Wang H-J, Fan J, Papadopoulos V. Translocator protein (TSPO) gene promoter-driven green fluorescent protein synthesis in transgenic mice: An in vivo model to study Tspo transcription. Cell Tissue Res 2012:350;261-275.

64. Morohaku K, Phuong NS, Selvaraj V. Developmental expression of translocator protein/peripheral benzodiazepine receptor in reproductive tissues. PLoS One 2013: 8;e74509.

65. Amsterdam A, Suh BS. An inducible functional peripheral benzodiazepine receptor in mitochondria of steroidogenic granulosa cells. Endocrinology 1991:129;503-510.

66. Anholt R, Pedersen P, De Souza E, et al. The peripheraltype benzodiazepine receptor. Localization to the mitochondrial outer membrane. J Biol Chem 1986:261; 576-583.

67. Lacapère JJ, Papadopoulos V. Peripheral-type benzodiazepine receptor: Structure and function of a cholesterolbinding protein in steroid and bile acid biosynthesis. Steroids 2003:68;569-585.

68. Tu LN, Morohaku K, Manna PR, et al. Peripheral benzodiazepine receptor/translocator protein global knock-out mice are viable with no effects on steroid hormone biosynthesis. J Biol Chem 2014:289;27444-27454.

69. Morohaku K, Pelton SH, Daugherty DJ, et al. Translocator protein/peripheral benzodiazepine receptor is not required for steroid hormone biosynthesis. Endocrinology 2014: 155;89-97.

70. Selvaraj V, Stocco DM, Tu LN. Translocator protein (TSPO) and steroidogenesis: A reappraisal. Mol Endocrinol 2015:29;490-501.

71. Thompson CJ, Ross SM, Gaido KW. Di(n-butyl) phthalate impairs cholesterol transport and steroidogenesis in the fetal rat testis through a rapid and reversible mechanism. Endocrinology 2004:145;1227-1237. 
72. Papadopoulos V, Amri H, Li H, et al. Targeted disruption of the peripheral-type benzodiazepine receptor gene inhibits steroidogenesis in the R2C Leydig tumor cell line. J Biol Chem 1997:272;32129-32135.

73. Bauer MP, Bridgham JT, Langenau DM, et al. Conservation of steroidogenic acute regulatory (StAR) protein structure and expression in vertebrates. Mol Cell Endocrinol 2000:168;119-125.

74. Clark BJ, Stocco DM. Steroidogenic acute regulatory proteIThe StAR still shines brightly. Mol Cell Endocrinol 1997:134;1-8.

75. Manna PR, Kero J, Tena-Sempere M, et al. Assessment of mechanisms of thyroid hormone action in mouse Leydig cells: Regulation of the steroidogenic acute regulatory protein, steroidogenesis, and luteinizing hormone receptor function. Endocrinology 2001:142;319-331.

76. Hum DW, Miller WL. Transcriptional regulation of human genes for steroidogenic enzymes. Clin Chem 1993:39; 333-340.

77. Miller WL, Auchus RJ. The molecular biology, biochemistry, and physiology of human steroidogenesis and its disorders. Endocr Rev 2011:32;81-151.

78. Barlow NJ, Phillips SL, Wallace DG, et al. Quantitative changes in gene expression in fetal rat testes following exposure to di(n-butyl) phthalate. Toxicol Sci 2003:73;431441.

79. Rone MB, Fan J, Papadopoulos V. Cholesterol transport in steroid biosynthesis: Role of protein-protein interactions and implications in disease states. Biochim Biophys Acta 2009:1791;646-658.

80. Hauet T, Yao Z-X, Bose HS, et al. Peripheral-type benzodiazepine receptor-mediated action of steroidogenic acute regulatory protein on cholesterol entry into Leydig cell mitochondria. Mol Endocrinol 2005:19;540-554.

81. Payne AH, Hales DB. Overview of steroidogenic enzymes in the pathway from cholesterol to active steroid hormones. Endocr Rev 2013. http://press.endocrine.org/doi/ abs/10.1210/er.2003-0030?url_ver=Z39.88-2003\&rfr_id= ori:rid:crossref.org\&rfr_dat=cr_pub\%3Dpubmed

82. Johnson KJ, McDowell EN, Viereck Mp, et al. Speciesspecific dibutyl phthalate fetal testis endocrine disruption correlates with inhibition of SREBP2-dependent gene expression pathways. Toxicol Sci 2011:120;460-474.

83. Thompson CJ, Ross SM, Hensley J, et al. Differential steroidogenic gene expression in the fetal adrenal gland versus the testis and rapid and dynamic response of the fetal testis to di(n-butyl) phthalate. Biol Reprod 2005:73;908917.

84. Ellis GB, Desjardins C, Fraser HM. Control of pulsatile LH release in male rats. Neuroendocrinology 1983:37;177-183.

85. Chandrashekar V, Bartke A. The role of growth hormone in the control of gonadotropin secretion in adult male rats. Endocrinology 1998:139;1067-1074.

86. Manson JM, Carr MC. Molecular epidemiology of hypospadias: Review of genetic and environmental risk factors. Birth Defects Res A Clin Mol Teratol 2003:67;825-836.

87. Nef S. Hormones in male sexual development. Genes Dev 2000:14;3075-3086.

88. Huhtaniemi I, Pelliniemi LJ. Fetal Leydig cells: Cellular origin, morphology, life span, and special functional features. Proc Soc Exp Biol Med 1992:201;125-140.

89. Rouiller-Fabre V, Muczynski V, Lambrot R, et al. Ontogenesis of testicular function in humans. Folia Histochem Cytobiol 2009:47;S19-S24.
90. Borch J, Ladefoged O, Hass U, et al. Steroidogenesis in fetal male rats is reduced by DEHP and DINP, but endocrine effects of DEHP are not modulated by DEHA in fetal, prepubertal and adult male rats. Reprod Toxicol 2004:18;53-61.

91. Heemers HV, Verhoeven G, Swinnen JV. Androgen activation of the sterol regulatory element-binding protein pathway: Current insights. Mol Endocrinol 2006:20;2265-2277.

92. Murashima A, Kishigami S, Thomson A, et al. Androgens and mammalian male reproductive tract development. Biochim Biophys Acta 2015:1849;163-170.

93. Rey RA, Codner E, Iñíguez G, et al. Low risk of impaired testicular Sertoli and Leydig cell functions in boys with isolated hypospadias. J Clin Endocrinol Metab 2005:90; 6035-6040.

94. Kalfa N, Liu B, Klein O, et al. Genomic variants of ATF3 in patients with hypospadias. J Urol 2008:180;21832188; discussion 2188.

95. Wolf C, Lambright C, Mann P, et al. Administration of potentially antiandrogenic pesticides (procymidone, linuron, iprodione, chlozolinate, p, $\mathrm{p}^{\prime}$-DDE, and ketoconazole) and toxic substances (dibutyl- and diethylhexyl phthalate, PCB 169 , and ethane dimethane sulphonate) during sexual differen. Toxicol Ind Health 1999:15;94-118.

96. Kalfa N, Philibert P, Sultan C. Is hypospadias a genetic, endocrine or environmental disease, or still an unexplained malformation? Int J Androl 2009:32;187-197.

97. Klip H, Verloop J, van Gool JD, et al. Hypospadias in sons of women exposed to diethylstilbestrol in utero: A cohort study. Lancet 2002:359;1102-1107.

98. Brouwers MM, Feitz WFJ, Roelofs LAJ, et al. Risk factors for hypospadias. Eur J Pediatr 2007:166;671-678.

99. Wang M-H, Baskin LS. Endocrine disruptors, genital development, and hypospadias. J Androl 2008:29;499-505.

100. Blaschko SD, Cunha GR, Baskin LS. Molecular mechanisms of external genitalia development. Differentiation 2012:84;261-268.

101. Morales-Suárez-Varela MM, Toft GV, Jensen MS, et al. Parental occupational exposure to endocrine disrupting chemicals and male genital malformations: A study in the Danish National Birth Cohort study. Environ Health 2011:10;3.

102. Bowman CJ, Barlow NJ, Turner KJ, et al. Effects of in utero exposure to finasteride on androgen-dependent reproductive development in the male rat. Toxicol Sci 2003:74; 393-406.

103. Rhees RW, Kirk BA, Sephton S, et al. Effects of prenatal testosterone on sexual behavior, reproductive morphology and LH secretion in the female rat. Dev Neurosci 1997: 19;430-437.

104. Macleod DJ, Sharpe RM, Welsh M, et al. Androgen action in the masculinization programming window and development of male reproductive organs. Int J Androl 2010:33; 279-287.

105. McIntyre BS, Barlow NJ, Wallace DG, et al. Effects of in utero exposure to linuron on androgen-dependent reproductive development in the male $\mathrm{Crl}: \mathrm{CD}(\mathrm{SD}) \mathrm{BR}$ rat. Toxicol Appl Pharmacol 2000:167;87-99.

106. McIntyre BS, Barlow NJ, Foster PM. Androgen-mediated development in male rat offspring exposed to flutamide in utero: Permanence and correlation of early postnatal changes in anogenital distance and nipple retention with malformations in androgen-dependent tissues. Toxicol Sci 2001:62;236-249. 
107. Swan SH, Sathyanarayana S, Barrett ES, et al. First trimester phthalate exposure and anogenital distance in newborns. Hum Reprod 2015:30;963-972.

108. Bornehag C-G, Carlstedt F, Jönsson BA, et al. Prenatal phthalate exposures and anogenital distance in Swedish boys. Environ Health Perspect 2015:123;101-107.

109. Suzuki Y, Yoshinaga J, Mizumoto Y, et al. Foetal exposure to phthalate esters and anogenital distance in male newborns. Int J Androl 2012:35;236-244.

110. Jurewicz J, Hanke W. Exposure to phthalates: Reproductive outcome and children health. A review of epidemiological studies. Int J Occup Med Environ Health 2011: 24;115-141.

111. Baskin LS, Himes K, Colborn T. Hypospadias and endocrine disruption: Is there a connection? Environ Health Perspect 2001:109;1175-1183.

112. Arbuckle TE, Hauser R, Swan SH, et al. Meeting report: Measuring endocrine-sensitive endpoints within the first years of life. Environ Health Perspect 2008:116;948-951.

113. Dean A, Sharpe RM. Clinical review: Anogenital distance or digit length ratio as measures of fetal androgen exposure: Relationship to male reproductive development and its disorders. J Clin Endocrinol Metab 2013:98;2230-2238.

114. Barrett ES, Parlett LE, Redmon JB, et al. Evidence for sexually dimorphic associations between maternal characteristics and anogenital distance, a marker of reproductive development. Am J Epidemiol 2014:179;57-66.

115. Mendiola J, Roca M, Mínguez-Alarcón L, et al. Anogenital distance is related to ovarian follicular number in young Spanish women: A cross-sectional study. Environ Health 2012:11;90.

116. Noriega NC, Ostby J, Lambright C, et al. Late gestational exposure to the fungicide prochloraz delays the onset of parturition and causes reproductive malformations in male but not female rat offspring. Biol Reprod 2005: $72 ; 1324-1335$.

117. OECD. Test No. 443: Extended one-generation reproductive toxicity study [Internet]. Paris: OECD Publishing; 2012. doi:10.1787/9789264185371-en

118. Skakkebaek NE, Rajpert-De Meyts E, Main KM. Testicular dysgenesis syndrome: An increasingly common developmental disorder with environmental aspects. Hum Reprod 2001:16;972-978.

119. Thorup J, McLachlan R, Cortes D, et al. What is new in cryptorchidism and hypo-padias - A critical review on the testicular dysgenesis hypothesis. J Pediatr Surg 2010:45; 2074-2086.

120. Eisenberg ML, Hsieh MH, Walters RC, et al. The relationship between anogenital distance, fatherhood, and fertility in adult men. PLoS One 2011:6; 18973.

121. Asklund C, Jensen TK, Main KM, et al. Semen quality, reproductive hormones and fertility of men operated for hypospadias. Int J Androl 2010:33;80-87.

122. Bracka A. A long-term view of hypospadias. Br J Plast Surg 1989:42;251-255.

123. Mendiola J, Stahlhut RW, Jørgensen N, et al. Shorter anogenital distance predicts poorer semen quality in young men in Rochester, New York. Environ Health Perspect 2011:119;958-963.

124. Cowin PA, Gold E, Aleksova J, et al. Vinclozolin exposure in utero induces postpubertal prostatitis and reduces sperm production via a reversible hormone-regulated mechanism. Endocrinology 2010:151;783-792.
125. National Toxicology Program, U.S. Department of Health and Human Services, Center for the Evaluation of Risks to Human Reproduction. Multigenerational reproductive assessment by continuous breeding when diethylhexylphthalate (CAS 117-81-7); 2005.

126. Mylchreest E, Cattley RC, Foster PMD. Male reproductive tract malformations in rats following gestational and lactational exposure to di(n-butyl) phthalate: An antiandrogenic mechanism? Toxicol Sci 1998:43;47-60.

127. Akingbemi BT. Modulation of rat Leydig cell steroidogenic function by di(2-ethylhexyl)phthalate. Biol Reprod 2001:65;1252-1259.

128. Welsh M, Saunders PTK, Fisken M, et al. Identification in rats of a programming window for reproductive tract masculinization, disruption of which leads to hypospadias and cryptorchidism. J Clin Invest 2008:118;1479-1490.

129. Ema M. Antiandrogenic effects of dibutyl phthalate and its metabolite, monobutyl phthalate, in rats. Congenit Anom (Kyoto) 2002:42;297-308.

130. Peters JM, Taubeneck MW, Keen CL, et al. Di(2ethylhexyl) phthalate induces a functional zinc deficiency during pregnancy and teratogenesis that is independent of peroxisome proliferator-activated receptor-alpha. Teratology 1997:56;311-316.

131. Lee Y, Yu X, Gonzales F, Mangelsdorf DJ, Wang M-Y, Richardson C, Witters LA, and Unger RH. PPAR $\alpha$ is necessary for the lipopenic action of hyperleptinemia on white adipose and liver tissue. PNAS 2002:99;11848-11853.

132. Barak Y, Nelson MC, Ong ES, et al. PPAR gamma is required for placental, cardiac, and adipose tissue development. Mol Cell 1999:4: 585-595.

133. Lapinskas PJ, Brown S, Leesnitzer LM, et al. Role of PPAR $\alpha$ in mediating the effects of phthalates and metabolites in the liver. Toxicology 2005:207;149-163.

134. Shipley JM, Waxman DJ. Simultaneous, bidirectional inhibitory crosstalk between PPAR and STAT5b. Toxicol Appl Pharmacol 2004:199;275-284.

135. Dunaif A, Scott D, Finegood D, et al. The insulinsensitizing agent troglitazone improves metabolic and reproductive abnormalities in the polycystic ovary syndrome. J Clin Endocrinol Metab 1996:81;3299-3306.

136. Bloomgarden ZT, Futterweit W, Poretsky L. Use of insulinsensitizing agents in patients with polycystic ovary syndrome. Endocr Pract 2001:7;279-286.

137. Vierhapper H, Nowotny $P$, Waldhäusl W. Reduced production rates of testosterone and dihydrotestosterone in healthy men treated with rosiglitazone. Metabolism 2003:52; 230-232.

138. Kempná P, Hofer G, Mullis PE, et al. Pioglitazone inhibits androgen production in NCI-H295R cells by regulating gene expression of CYP17 and HSD3B2. Mol Pharmacol 2007:71;787-798.

139. Gasic S, Bodenburg Y, Nagamani M, et al. Troglitazone inhibits progesterone production in porcine granulosa cells. Endocrinology 1998:139;4962-4966.

140. Mu YM, Yanase T, Nishi Y, et al. Insulin sensitizer, troglitazone, directly inhibits aromatase activity in human ovarian granulosa cells. Biochem Biophys Res Commun 2000: 271;710-713.

141. Arlt W, Auchus RJ, Miller WL. Thiazolidinediones but not metformin directly inhibit the steroidogenic enzymes P450c17 an- 3beta-hydroxysteroid dehydrogenase. J Biol Chem 2001:276;16767-16771. 
142. Minge CE, Robker RL, Norman RJ. PPAR gamma: Coordinating metabolic and immune contributions to female fertility. PPAR Res 2008:2008;243791.

143. Gasic S, Nagamani M, Green A, et al. Troglitazone is a competitive inhibitor of 3beta-hydroxysteroid dehydrogenase enzyme in the ovary. Am J Obstet Gynecol 2001: 184;575-579.

144. Veldhuis JD, Zhang G, Garmey JC. Troglitazone, an insulin-sensitizing thiazolidinedione, represses combined stimulation by $\mathrm{LH}$ and insulin of de novo androgen biosynthesis by thecal cells in vitro. J Clin Endocrinol Metab 2002:87;1129-1133.

145. Couto JA, Saraiva KLA, Barros CD, et al. Effect of chronic treatment with Rosiglitazone on Leydig cell steroidogenesis in rats: In vivo and ex vivo studies. Reprod Biol Endocrinol 2010:8;13.

146. Mathieu-Denoncourt J, Wallace SJ, de Solla SR, et al. Plasticizer endocrine disruption: Highlighting developmental and reproductive effects in mammals and non-mammalian aquatic species. Gen Comp Endocrinol 2015:219;74-88.

147. Martinez-Arguelles DB, Papadopoulos V. Identification of hot spots of DNA methylation in the adult male adrenal in response to in utero exposure to the ubiquitous endocrine disruptor plasticizer di-(2-ethylhexyl) phthalate. Endocrinology 2015:156;124-133.

148. Abdel-Maksoud FM, Leasor KR, Butzen K, et al. Prenatal exposures of male rats to the environmental chemicals bisphenol a and di(2-ethylhexyl) phthalate impact the sexual differentiation process. Endocrinology 2015:156; 4672-4683.

149. Hauser R, Gaskins AJ, Souter I, et al. Urinary phthalate metabolite concentrations and reproductive outcomes among women undergoing in vitro fertilization: Results from the EARTH study. Environ Health Perspect 2015: 124;831-839.

150. Hauser R, Calafat A. Phthalates and human health. Occup Environ Med 2005:62;806-818.

151. Lioy PJ, Hauser R, Gennings C, et al. Assessment of phthalates/phthalate alternatives in children's toys and childcare articles: Review of the report including conclusions and recommendation of the Chronic Hazard Advisory Panel of the Consumer Product Safety Commission. J Expo Sci Environ Epidemiol 2015:25;343-353.

152. Wittassek M, Angerer J, Kolossa-Gehring M, et al. Fetal exposure to phthalates-A pilot study. Int J Hyg Environ Health 2009:212;492-498.

153. Calafat AM, Brock JW, Silva MJ, et al. Urinary and amniotic fluid levels of phthalate monoesters in rats after the oral administration of di(2-ethylhexyl) phthalate and din-butyl phthalate. Toxicology 2006:217;22-30.

154. Swan SH. Environmental phthalate exposure in relation to reproductive outcomes and other health endpoints in humans. Environ Res 2008:108;177-184.

155. Huang P-C, Kuo P-L, Chou Y-Y, et al. Association between prenatal exposure to phthalates and the health of newborns. Environ Int 2009:35;14-20.

156. Thankamony A, Lek N, Carroll D, et al. Anogenital distance and penile length in infants with hypospadias or cryptorchidism: Comparison with normative data. Environ Health Perspect 2013:122;207-211.
157. Hsieh MH, Breyer BN, Eisenberg ML, et al. Associations among hypospadias, cryptorchidism, anogenital distance, and endocrine disruption. Curr Urol Rep 2008: $9 ; 137-142$.

158. Corton JC, Cunningham ML, Hummer BT, et al. Mode of action framework analysis for receptor-mediated toxicity: The peroxisome proliferator-activated receptor alpha (PPAR $\alpha$ ) as a case study. Crit Rev Toxicol 2014:44; $1-49$.

159. Wood CE, Jokinen MP, Johnson CL, et al. Comparative time course profiles of phthalate stereoisomers in mice. Toxicol Sci 2014:139;21-34.

160. JRC. Screening methodology to identify potential endocrine disruptors according to different options in the context of an impact assessment. EUR 27955 EN, Luxembourg: Publications Office of the European Union, 2016, DOI: $10.2788 / 73203$.

161. Hurst $\mathrm{CH}$, Waxman DJ. Activation of PPARalpha and PPARgamma by environmental phthalate monoesters. Toxicol Sci 2003:74;297-308.

162. Bility MT, Thompson JT, McKee RH, et al. Activation of mouse and human peroxisome proliferator-activated receptors (PPARs) by phthalate monoesters. Toxicol Sci 2004:82;170-182.

163. Svechnikov K, Svechnikova I, Söder O. Inhibitory effects of mono-ethylhexyl phthalate on steroidogenesis in immature and adult rat Leydig cells in vitro. Reprod Toxicol 2008:25;485-490.

164. Desdoits-Lethimonier C, Albert O, Le Bizec B, et al Human testis steroidogenesis is inhibited by phthalates. Hum Reprod 2012:27;1451-1459.

165. Shultz VD. Altered gene profiles in fetal rat testes after in utero exposure to di(n-butyl) phthalate. Toxicol Sci 2001: 64;233-242.

166. Andrade AJM, Grande SW, Talsness CE, et al. A dose response study following in utero and lactational exposure to di-(2-ethylhexyl) phthalate (DEHP): Reproductive effects on adult male offspring rats. Toxicology 2006:228; 85-97.

167. Jarfelt K, Dalgaard M, Hass U, et al. Antiandrogenic effects in male rats perinatally exposed to a mixture of di(2-ethylhexyl) phthalate and di(2-ethylhexyl) adipate. Reprod Toxicol 2005:19;505-515.

168. Petersen RV. Toxicology of plastic devices having contact with blood. NTIS Report (PB-250 102), 1975.

169. Clewell RA, Campbell JL, Ross SM, et al. Assessing the relevance of in vitro measures of phthalate inhibition of steroidogenesis for in vivo response. Toxicol In Vitro 2010:24;327-334.

Address correspondence to: Sharon Munn

European Commission

Joint Research Centre (JRC)

Directorate F-Health, Consumers and Reference Materials, Chemical Safety and Alternative Methods I-21027 Ispra (VA) Italy

E-mail: sharon.munn@ec.europa.eu 